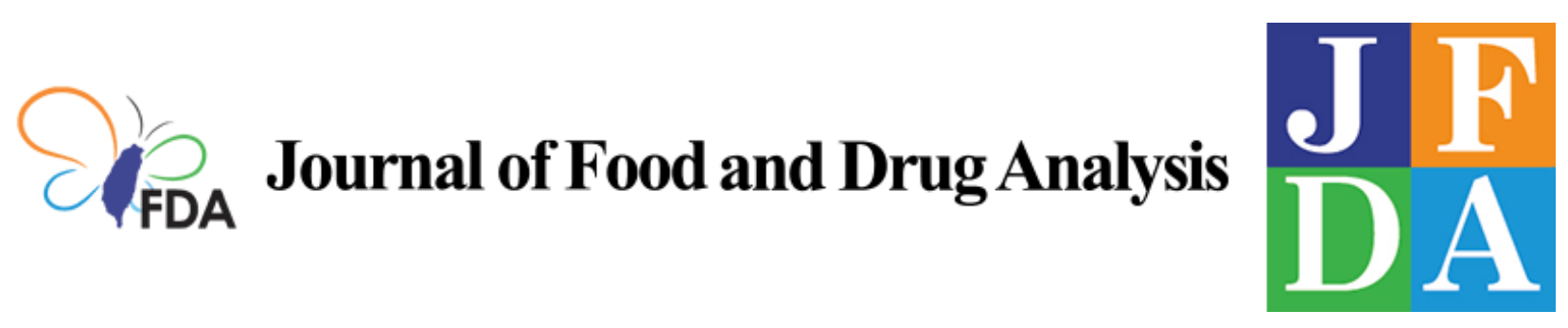

Volume 28 | Issue 4

Article 11

2020

\title{
Nanomaterial-based adsorbents and optical sensors for illicit drug analysis
}

Follow this and additional works at: https://www.jfda-online.com/journal

Part of the Food Science Commons, Medicinal Chemistry and Pharmaceutics Commons, Pharmacology Commons, and the Toxicology Commons

(c) (i) (9)

This work is licensed under a Creative Commons Attribution-Noncommercial-No Derivative Works 4.0 License.

\section{Recommended Citation}

Chen, Chun-Hsien; Wang, Chun-Chi; Ko, Po-Yun; and Chen, Yen-Ling (2020) "Nanomaterial-based adsorbents and optical sensors for illicit drug analysis," Journal of Food and Drug Analysis: Vol. 28 : Iss. 4 , Article 11.

Available at: https://doi.org/10.38212/2224-6614.1137

This Review Article is brought to you for free and open access by Journal of Food and Drug Analysis. It has been accepted for inclusion in Journal of Food and Drug Analysis by an authorized editor of Journal of Food and Drug Analysis. 
Nanomaterial-based adsorbents and optical sensors for illicit drug analysis

Cover Page Footnote

We gratefully acknowledge the support of the Ministry of Science and Technology of Taiwan (MOST

109-2113-M-194-011) for funding this work. 


\title{
Nanomaterial-based adsorbents and optical sensors for illicit drug analysis
}

\author{
Chun-Hsien Chen ${ }^{a}$, Chun-Chi Wang ${ }^{a, e}$, Po-Yun Ko ${ }^{b}$, Yen-Ling Chen ${ }^{\mathrm{c}, \mathrm{d}, \mathrm{e}, *}$ \\ a School of Pharmacy, College of Pharmacy, Kaohsiung Medical University, Kaohsiung, Taiwan \\ ${ }^{\mathrm{b}}$ Post Baccalaureate Medicine, College of Medicine, Kaohsiung Medical University, Kaohsiung, Taiwan \\ ${ }^{\mathrm{c}}$ Department of Chemistry and Biochemistry, National Chung Cheng University, Chia-Yi, Taiwan \\ d Department of Fragrance and Cosmetic Science, College of Pharmacy, Kaohsiung Medical University, Kaohsiung, Taiwan \\ ${ }^{\mathrm{e}}$ Development and Value Creation Research Center, Kaohsiung Medical University, Kaohsiung, Taiwan
}

\begin{abstract}
The abuse of illicit drugs has been prevalent in recent years and is associated with crime and public health issues. To strengthen public security and fortify public health services with respect to the increasing severity of drug abuse, academic and government institutes have been devoted to constructing relative analytical methods for illicit drugs. To date, the development of sensors has been greatly emphasized due to their features of high sensitivity, prompt detection and flexible manipulation; thus, sensors can serve as alternatives to conventional sophisticated instruments. Recently, the use of nanomaterials has inspired the development of a series of innovative sample pretreatment and detection strategies in the field of analytical chemistry. Herein, this review elaborated the application of nanomaterials in analytical methods, including sample pretreatments, colorimetric sensors and fluorescent sensors. The utilization of nanomaterials in the analytical field provides novel perspectives for the development of detection platforms and facilitates the monitoring of illicit drugs in diverse complex matrices.
\end{abstract}

Keywords: Nanomaterial, Adsorbents, Colorimetric sensors, Fluorescent sensors, Illicit drugs

\section{Introduction}

$\mathrm{T}$ he prevalence of drug abuse has become a severe public health issue and a serious criminal issue worldwide in recent years. Illicit drugs accompanied by addiction, organ dysfunction and fatality at high doses are categorized on the basis of their traits as depressants, stimulants, narcotics or hallucinogens [1]. The abuse of these drugs can gradually deteriorate the mental or physical condition of users. The United Nations Office on Drugs and Crime reported that an enormous number of individuals, up to 188 million, have used cannabis as a hallucinogen at least once. Stimulants, such as cocaine, amphetamine and methamphetamine, are the second most abused drugs, with 68 million users. Among them, cocaine accounted for 18 million users in 2017. Furthermore, 50 million individuals worldwide had taken up opioids in 2017 [2]. In Taiwan, the data according to the Analytic Laboratory Drug Abuse Report System from 1999-2011 also showed that methamphetamine was the most widely abused drugs [3]. According to the annual statistic of abusing drugs in 2018 in Taiwan, 36,746 individuals who were influenced by illicit drugs were reported, which presented an increasing trend from 2016 to 2018. Moreover, the cases of polypharmacy were also determined to be up to $73 \%$. Among these cases, the dual combination of illicit drugs accounts for $81.2 \%$ of multiple drug abuse. Methamphetamine and 3, 4-methylenedioxy-methamphetamine (MDMA) were the most prevalent drugs used in dual combination.

Received 24 May 2020; Received in revised form 23 August 2020; accepted 18 September 2020.

Available online 1 December 2020

* Corresponding author at: Department of Chemistry and Biochemistry, National Chung Cheng University, Chia-Yi, Taiwan. Fax: 88652721040.

E-mail address: yelichen@ccu.edu.tw (Y.-L. Chen). 
Other illicit drugs can be also found in multiple drug abuse, such as ketamine, norketamine, morphine and codeine [4]. To efficiently control the extending prevalence of drug abuse, the government in Taiwan also legislated cut-off levels of illicit drugs in human urine which presented in Table 1 [5,6]. Regulations in EU and USA corresponding to that in Taiwan are also listed in the table [7-9].

The main test methods for determining the presence of illicit drugs in medical and government institutions include liquid chromatography coupled with (tandem) mass spectrometry (LC-MS or LCMS/MS) [10,11], gas chromatography coupled with mass spectrometry (GC-MS) [12] and immunoassays [13], which are commercially available and widely utilized for monitoring the levels of illicit drugs. In recent decades, the nanomaterial-based analytical techniques have become a novel trend in illicit drug analysis. Nanomaterials possess unique characteristics such as high surface area, ease of modification, which can perform diverse application, such as sample pretreatment and biosensor establishment, so as to facilitate the monitoring illicit drugs.

To monitor the levels of illicit drugs efficiently, the sample pretreatment procedure is a crucial factor to obtain ideal performance on detection. Nevertheless, the elimination of interferences from complex matrices may be challenged for the detection of illicit drugs because the detection usually implemented in human body fluids (blood, urine, hair and saliva ...), foods and beverages which compose of varied compounds.

Sample pretreatment coupled with nanometer-sized magnetic nanoparticles (MNPs), can provide faster phase separation by applying an external magnetic field and be easy to reuse. MNPs also can be utilized to generate a high selectivity, facile extraction procedure, less reagent consumption compared to conventional sample pretreatment methods.

In addition to sample pretreatment methods, nanomaterials can also be applied as signal reporters that provide rapid and sensitive detection. Nanomaterial-based optical sensor systems can be categorized into colorimetric and fluorescent sensor systems. In colorimetric methods, noble metal nanoparticles, namely gold and silver, were universally utilized nanomaterials attributed to their unique optical property of surface plasmon resonance (SPR) [14,15]. The phenomenon of SPR facilitates the visual observation of the color change of nanomaterials when the analyte is added into the detection system. Regarding fluorescent methods, nanomaterials were utilized to develop a versatile detection strategy. These kinds of nanomaterials, such as nanoclusters (NCs), quantum dots (QDs), carbon dots (CDs) and upconversion nanoparticles (UCNPs), possess the trait of tunable luminescent emission, which can be substituted for conventional fluorescent indicators such as fluorescein (FAM), cyanine 3 (Су3), carboxytetramethylrhodamine (TAMRA), carboxy-X-rhodamine (ROX), etc [16-19].

Attributed to the development of novel sensors, further evolution has also implemented a series of rapid diagnostic strategies for illicit drugs in combination with nanomaterials. This review mainly emphasizes the analytical techniques among nanomaterial-based adsorbents, nanomaterial-based colorimetric sensor systems and fluorescent sensors for the detection of illicit drugs.

\section{Surface functionalized MNPs}

Magnetic solid-phase extraction (MSPE) was first established in 1999 by Šafařõková et al. using

Table 1. Regulations of cut-off levels of illicit drugs in Taiwan, EU and USA.

\begin{tabular}{|c|c|c|c|c|c|}
\hline & \multirow{2}{*}{$\frac{\text { Taiwan }\left(\text { TFDA }^{1}\right)}{\text { Urine }(\mathrm{ng} / \mathrm{mL})}$} & \multicolumn{2}{|l|}{$\mathrm{EU}\left(\mathrm{EMCDDA}^{2}\right)$} & \multicolumn{2}{|l|}{ USA $\left(\mathrm{HHS}^{3}\right)$} \\
\hline & & Whole blood (ng/mL) & Oral fluid (ng/mL) & Urine $(\mathrm{ng} / \mathrm{mL})$ & Oral fluid $(\mathrm{ng} / \mathrm{mL})$ \\
\hline Benzodiazepines & 100 & $140_{\text {(Diazepam) }}$ & 5 (Diazepam) & - & - \\
\hline Amphetamine & 500 & 20 & 360 & 250 & 25 \\
\hline Methamphetamine & 500 & 20 & 410 & 250 & 25 \\
\hline MDMA & 500 & 20 & 270 & 250 & 25 \\
\hline Morphine & 300 & 10 & 95 & 2000 & 15 \\
\hline Codeine & 300 & 10 & 94 & 2000 & 15 \\
\hline Cocaine & - & 10 & 170 & - & 8 \\
\hline Benzoylecgonine & 150 & 50 & 95 & 100 & 8 \\
\hline Ketamine & 100 & - & - & - & - \\
\hline Norketamine & 100 & - & - & - & - \\
\hline THC & 15 & 1.0 & 27 & 15 & 2 \\
\hline
\end{tabular}

Abbreviation: ${ }^{1}$ TFDA: Food and Drug Administration (Taiwan), ${ }^{2}$ EMCDDA: European Monitoring Centre for Drugs and Drug Addiction, ${ }^{3}$ HHS: United States Department of Health and Human Services. 
magnetic charcoal as an adsorbent [20]. MSPE is a novel technique that accomplishes extraction by the interaction between the functional group on the surface-modified magnetic material as the adsorbent and the analytes. Compared to conventional magnetic beads, nanometer-sized magnetic particles possess the properties of superparamagnetism, better dispersibility and higher surface area, which enhance the extraction efficiency [21]. In order to overcome the problems, such as complex matrices and time-consuming sample preparation, techniques on the basis of surface functionalized MNPs were developed to extract illicit drugs. Previous studies are summarized in Table 2 which presented extraction condition corresponding to each adsorbent in illicit drugs analysis.

\subsection{Small organic molecules}

The magnetic core of magnetic nanoparticles (MNPs) is mainly composed of iron, nickel, cobalt and their oxides. In conventional MNPs, small organic molecules were used to modify iron oxide MNPs, including carbon [22,23], methacrylic acid-3(trimethoxysilyl) propyl ester (MPS) [24,25], which influences the ability of the adsorbent to capture illicit drugs such as methamphetamine [13,23], cocaine [24] and morphine [25] in urine or hair samples. The interaction between analytes and surface-modified magnetic nanoparticles was implemented by van der Waals forces, $\pi-\pi$ stacking interactions, and hydrophobic or electrostatic interactions.

Boojaria et al. synthesized MPS-modified MNPs for extracting morphine from human hair. The pretreated $50 \mathrm{mg}$ of hair sample was rinsed with ethanol and the solution was subsequently diluted with deionized water. After that, morphine was spiked into the treated hair solution. The recovery of morphine in hair solution by using MPS-modified MNPs was obtained to be $87.62 \%$. Moreover, an enrichment factor of 208 was acquired by this method, which enhanced the detection sensitivity up to $0.1 \mathrm{ng} / \mathrm{mL}$ as the limit of detection (LOD) by HPLC-UV [25].

\subsection{Polymer}

The surface of fabricated MNPs from polymer are better than small molecules. It is found to have significant advantages, such as high stability in suspension. Haeri et al. established a biodispersive liquid-liquid microextraction (bio-DLLME) based on polypyrrole-coated iron oxide nanoparticles for methamphetamine extraction in urine [26]. The urine sample was first treated with polypyrrolecoated iron oxide nanoparticles, and the desorption solution containing methamphetamine was further extracted by a rhamnolipid biosurfactant. The LOD was measured to be $0.33 \mathrm{ng} / \mathrm{mL}$ by HPLC-UV and an enrichment factor of 310 within 2 min of extraction time. In addition, carbon nanotubes (CNTs) $[27,28]$ and graphene oxide (GO) $[29,30]$ were also utilized as composites with iron oxide MNPs. CNTs and GO provide $\pi-\pi$ stacking interactions and chelation sites for hydrogen bonds, respectively, to aromatic compounds such as methamphetamine, cocaine, ketamine, codeine and morphine [27-30]. The MSPE method, based on a magnetite/rGO/silver nanocomposite, was utilized for the extraction of codeine and morphine. The nanomaterials with high surface areas, suitable chemical surfaces and functional groups as adsorbed sites provided superior enrichment factors for analytes up to 1000 with a 15 min extraction time. The enrichment factor of the novel MSPE method is much higher than that obtained by conventional DLLME in the range of 63-85 [29].

\subsection{Aptamer and antibody}

The utilization of specific ligand, namely aptamer and antibody, as the extraction agent for illicit drugs provide specificity on sample pretreatment procedure. This kind of ligand can capture certain target from complex matrix and avoid interferences during detection. Aptamers, short single-strand DNA or RNA, can recognize analytes and increase the specificity of the extraction procedure. They are easy to obtain and more stable with respect to biodegradation. Du et al. developed a colorimetric sensor system for detecting cocaine [31]. Cocaine aptamers were modified on amine-functionalized MNPs and another cocaine aptamer with hemin-G-quadruplexes hydrides with cocaine aptamer-modified MNPs when cocaine was present simultaneously. The aptasensor can capture the cocaine within a complex matrix by aptamer-modified MNPs in an external magnetic field. Hemin-G-quadruplex can catalyze the 3,3,5,5-tetramethylbenzidine sulfate (TMB)-hydrogen peroxide system to trigger the color change of TMB from colorless to yellow. Using the aptasensor mechanism, cocaine can be quantified according to the TMB color change. In addition to aptamers, antibodies also have a high affinity for selective targets. When antibody-modified MNPs are prepared, amphetamine and methamphetamine can be purified from urine samples and analyzed by matrix-assisted laser desorption ionization time-offlight mass spectrometer (MALDI-TOF MS) analysis [32]. Compared with other methods using surface functionalized MNPs, only 20-25 $\mu \mathrm{L}$ sample and 
Table 2. Various magnetic nanomaterial-based adsorbents for analysis of illicit drugs.

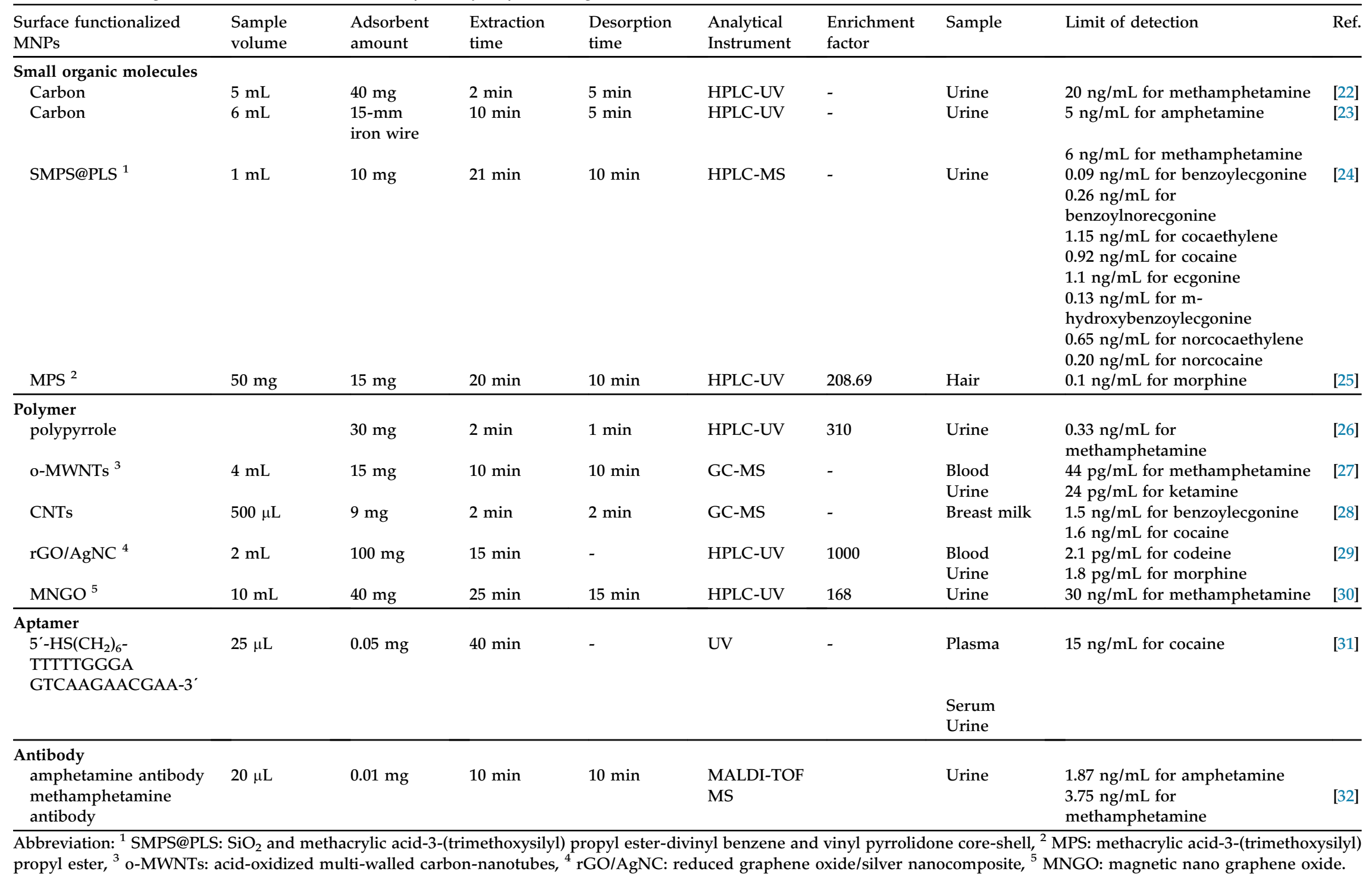

propyl ester, ${ }^{3}$ o-MWNTs: acid-oxidized multi-walled carbon-nanotubes, ${ }^{4}$ rGO/AgNC: reduced graphene oxide/silver nanocomposite, ${ }^{5}$ MNGO: magnetic nano graphene oxide. 
0.01-0.05 mg adsorbent were needed when using aptamers or antibodys modified MNPs in illicit drug analysis. The ligand as the adsorbent with magnetic materials can be flexibly selected according to the target analytes by different synthesis protocols. Moreover, the cooperation of the aptamer and antibody provide the specificity of extraction, less sample and adsorbent consuming which also possesses a greater tendency to eliminate interference from the complex matrix.

In summary, magnetic nanomaterials-based adsorbents provide facile and flexible modification which can utilize to capture diverse illicit drugs. According to the efficiency of eliminating sample interferences integrated in Table 2, a large sample volume in the range of milliliter can be extracted and eluted with a small amount of solvent in few microliter. External magnetic field play an important role on capturing magnetic adsorbent binding with analyte so as to eliminate the sample matrix. The sample pretreatment by nanomaterials achieves not only effective separation of analyte from complex matrices but also pre-concentration of sample solution for signal amplification. In addition, the reusability of nanomaterials-based adsorbents was potentially available which was indicated in several literatures, such as five times-reused divinyl benzene and vinyl pyrrolidone functionalized silanized MNPs with acceptable recovery above $76.9 \%$ [24] and eighty continuous adsorption-desorption cycles for magnetite/rGO/silver nanocomposite without losing substantial extraction efficiency [29]. In the part of detection sensitivity, several analytical methods coupled with magnetic nanomaterialsbased adsorbents can obtained LODs from 0.0018 to $20 \mathrm{ng} / \mathrm{mL}$ by HPLC-UV. Those obtained detection limits were close to LODs measured by MS system from 0.001 to $6 \mathrm{ng} / \mathrm{mL}$ with conventional LLE or SPE $[22,26,29]$. It means the sample pretreatment can effectively improve not only the efficiency of eliminating interferences from complex matrices but also enhance the sensitivity.

\section{Nanomaterial-based colorimetric sensors}

Colorimetric sensors are typically used in conjunction with nanoparticles due to their unique optical properties, surface dielectric environment and catalytic activity. AuNPs are one of the most iconic nanomaterials and have been widely applied in the establishment of colorimetric sensors due to their air stability and visible spectrum owing to d$\mathrm{d}$ band transitions [14]. The color change of different sizes of AuNPs can be observed via the influence on the plasmon oscillation while irradiating by light, namely, surface plasmon resonance (SPR) [33]. The colorimetric sensing systems developed to analyze illicit drugs were mainly small organic moleculesbased AuNP sensors and aptamer-based AuNP sensors.

\subsection{Small organic molecules-based AuNP sensors}

Many sensors functioning on the basis of ligand interaction or ligand exchange have been established for the detection of illicit drugs that possess functional groups that are prone to interact with the ligand on the surface of AuNPs. The mechanism of citrate-capped AuNPs for the detection of abused drugs can be divided into ligand exchange on the surface of AuNPs [34] or ligand interaction between citrate and the analyte $[35,36]$. The ligand exchange process can be performed due to the weak surfacebound citrate as the ionic stabilization agent for the AuNPs [37]. Consequently, the molecules with stronger affinity to AuNPs can competitively displace the binding sites of citrate to AuNPs. In ligand exchange, Lodha et al. developed a biosensor for the detection of codeine sulfate in bone, bone marrow and soil [34]. Codeine sulfate can displace the weakly bound citrate on the surface of AuNPs via ligand exchange and further coordinate with the surface of AuNPs by multiple binding sites, such as sulfate groups and oxygen hybrid rings. The aggregation of AuNPs can be observed in the presence of codeine sulfate as the bridge between the AuNPs. The LOD for codeine sulfate was $0.6 \mu \mathrm{g} / \mathrm{mL}$ by a digital camera of a mobile phone [34]. The other mechanism for the citrate-capped AuNPs relies on the direct interaction between citrate and the analyte by the cross-linking process. A colorimetric sensor array was established for the detection of opioid analogs (codeine, methadone, morphine, noroxycodone, oxycodone, thebaine and tramadol) in urine [35]. The opioids possess many hydrogen bond donor/acceptor sites, including hydroxyl, methoxy and furan-like oxygen hybrid rings, which provide the link between citrate and opioids to induce the aggregation of AuNPs. Consequently, the LOD of noroxycodeine was $6.7 \mu \mathrm{g} / \mathrm{mL}$, and others were as low as $0.29 \mu \mathrm{g} / \mathrm{mL}$ [35]. A similar biosensor was established by Bahram et al. for the detection of morphine, and the LOD was $0.15 \mu \mathrm{g} / \mathrm{mL}$ in serum and urine samples [36].

Previous studies have demonstrated that electronrich nitrogen-containing ligands possess high affinity for the surface of AuNPs [38], and melamine, as a nitrogen-containing ligand, has been widely applied in versatile detection strategies [39]. Lodha et al. fabricated a sensor for the detection of 
clonazepam in blood, bone and bone marrow samples based on the aggregation of AuNPs by the interaction between melamine and clonazepam, which brings AuNPs closer to each other. An LOD of $0.28 \mathrm{ng} / \mathrm{mL}$ can be obtained by evaluating the absorption ratio $\left(\mathrm{A}_{636} \mathrm{~nm} / \mathrm{A}_{552 \mathrm{~nm}}\right)$ [40]. A similar mechanism of melamine-modified AuNPs was also applied to quantify the content of codeine and morphine in human serum and urine samples, and the LODs of morphine and codeine were $4.9 \mathrm{ng} / \mathrm{mL}$ and $2.7 \mathrm{ng} / \mathrm{mL}$, respectively [41]. The incubation time of these colorimetric sensors were less than $10 \mathrm{~min}$.

\subsection{Aptamer-based AuNP sensors}

The mechanism of colorimetric biosensors on the basis of aptamers (or oligonucleotides) for the detection of targets with high selectivity mainly depends on the unique property of the binding interaction between aptamers and analytes. Once the analyte is present in the detection system, the aptamer can form a complex with the analyte, and this phenomenon produces a conformational change on an aptamer that fails to perform hybridization or electrostatic interactions with other substances, such as complementary DNA or AuNPs [42].

In the case of oligonucleotide-assisted aggregation, the color change attributed to the aggregation of AuNPs depends on the distance between the AuNPs [43]. Liu et al. designed 3'-thio-modified DNA and $5^{\prime}$-thio-modified DNA immobilized on AuNPs $(13 \mathrm{~nm})$, respectively. In the absence of cocaine, $3^{\prime}$-thio-modified DNA and $3^{\prime}$-thio-modified DNA were assembled with linker DNA and a cocaine aptamer. A passive aggregation of AuNPs was observed by the color change of AuNPs from red to purple due to the redshift of the SPR wavelength. Once cocaine is present, the aptamer interacts with the cocaine, and the $5^{\prime}$-thio-modified DNA cannot complement the linker DNA. A red color was still observed because the distance between the AuNPs did not shorten [44]. In addition, the mechanism of oligonucleotide-assisted aggregation was also applied to detect cocaine in latent fingerprints (LFPs) by nanoplasmonic imaging [45]. Cocaine aptamers with two single-strand DNA molecules modified on AuNPs form a stem-bulgestem structure when cocaine exists. The aggregation of AuNPs and color changes of the scattered light in the dark-field image of an LFP were observed. Consequently, the minimal detectable content of cocaine on LFPs was measured down to $90 \mathrm{ng}$ [45].
In addition to the aptasensor based on the passive oligonucleotide-assisted aggregation of AuNPs, the active aggregation of AuNPs, namely, salt-induced self-assembly, was also utilized to establish analytical methods for quantifying cocaine [46-49] and methamphetamine [50]. The strategy is based on the van der Waals attraction between the AuNPs themselves, which induces AuNP self-assembly, and assembly between aptamers and AuNPs, which can prevent the aggregation of AuNPs. In general, the surface of AuNPs was adsorbed with negative ions such as citrate, and they can inhibit the aggregation of AuNPs themselves. However, the addition of salt into the colloid can induce the selfaggregation of AuNPs due to the neutralization of citrate ions on the surface of AuNPs, which reduces the repulsion between AuNPs. This reaction produces the redshift of the absorption wavelength upon SPR, and the color change of the colloid can also be visually observed to change from red to purple. On the other hand, the oligonucleotide can attach to the surface of AuNPs, which creates repulsion between the nanoparticles. Consequently, the absorption wavelength would not transform even in a high salt concentration [42]. According to the theory, Zhang et al. established a colorimetric aptasensor for the detection of cocaine [46]. In the presence of cocaine, the complex, specific secondary structure formed due to the binding of cocaine to the aptamer [51] can resist the attachment of an aptamer onto the surface of AuNPs due to the outer phosphate backbone that can be described as dsDNA, resulting in self-aggregated AuNPs after the addition of salt. In contrast, the aptamer can interact with the surface of AuNPs by van der Waals attraction in the absence of cocaine. Consequently, the self-assembly of AuNPs can be inhibited after the addition of salt into the colloid. Finally, the LOD was $0.6 \mu \mathrm{g} / \mathrm{mL}$ [46]. Attributed to the visual change in the color of the AuNPs, prompt measurements of cocaine relying on RGB color codes by snapping photographs were also developed by Smith et al. and Wang et al. [48,49]. A similar mechanism of the aptasensor can also be fabricated for the detection of methamphetamine in urine samples, and an LOD of $0.12 \mu \mathrm{g} / \mathrm{mL}$ was achieved [50].

\subsection{Others}

A colorimetric sensor can be developed from the synthesis process of nanoparticles. Amjadi et al. fabricated a biosensor by enhancing the reduction of silver nanoparticles (AgNPs) with the addition of cannabinoids that possess a phenolic group so that they can provide mild reducing properties and 
coordinate the reducing agent of $\mathrm{AgNO}_{3}$ in the process of synthesis of AgNPs. As a result, the increasing SPR absorption peak of AgNPs can be observed, and this phenomenon can be further applied to quantify the species of cannabinoid [52]. Another colorimetric sensor, $\mathrm{Au} @ \mathrm{Ag}$ core-shell nanoparticles, was immobilized with partially corresponding complementary strands of aptamers (as a reporter probe) for the duplexed detection of methamphetamine. The capture probe, with a partially corresponding complementary strand of aptamers, conjugated with MNPs. In the absence of analytes, the reporter probe and capture probe bound to the aptamer and Au@Ag-DNA-MNP complex structures were formed. The intensity of the SPR absorption peak was lower than that in the presence of analytes [53]. A similar mechanism was used to simultaneously duplex the detection of methamphetamine and cocaine by observing multiple dominant wavelengths [54]. The Au@Ag coreshell nanoparticles were synthesized by the shell coating of silver onto the surface of AuNPs, which produced a blueshift of nanoparticles from $520 \mathrm{~nm}$ to $400 \mathrm{~nm}$. Moreover, the enhancement of absorption after the synthesis of Au@Ag core-shell nanoparticles was mainly due to surface plasmon damping. Finally, the LODs for methamphetamine and cocaine were measured to be $75 \mathrm{pg} / \mathrm{mL}$ and $1 \mathrm{ng} / \mathrm{mL}$, respectively [54]. In addition to the application of AgNPs and Au@Ag core-shell nanoparticles for colorimetric sensors, MNPs were also utilized to construct a rapid detection sensor based on a lateral flow strip for cocaine [55]. The principle of the sensor was dependent on the interaction between anti-cocaine antibody-modified MNPs and cocaine, which can influence the further reaction of MNPs to cocaine-BSA and goat anti-mouse IgG antibody immobilized on the surface of the lateral flow strip. After the reaction, two discriminable brown bands can be observed, and the color densities of the bands depend on the cocaine content. Consequently, the quantification of cocaine can be achieved by calculating the ratio of RGB color codes of two bands through a smart phone camera, with an LOD of $5 \mathrm{ng} / \mathrm{mL}$ [55]. Similar mechanism of lateral flow assay for cocaine was also conducted by benzoylecgonine $\mathrm{mAb}$ conjugated AuNPs and a LOQ at $10 \mathrm{ng} / \mathrm{mL}$ can be measured in synthetic saliva [56].

The following sensing mechanisms of nanomaterial-based colorimetric sensors are summarized and shown in Fig. 1: (1) ligated-analyte interaction, (2) oligonucleotide-assisted aggregation, (3) salt-induced self-assembly, and (4) others. In colorimetric biosensors, AuNPs are the most widely applied nanomaterials used to perform versatile detection strategies based on surface interactions and optical properties. With the ability to visually

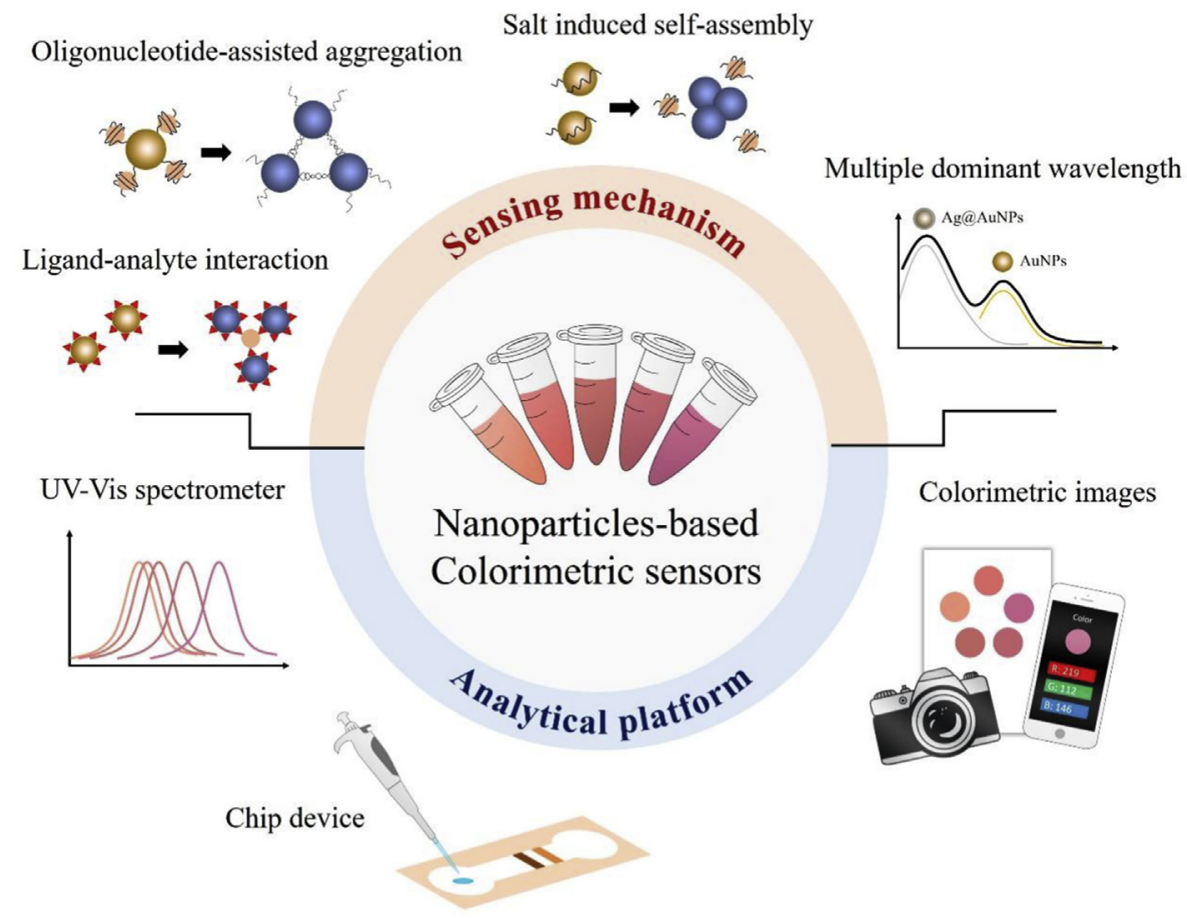

Fig. 1. Colorimetric strategies for illicit drugs based on nanomaterials which combine with versatile analytical platforms. 
observe the color change of AuNPs or chromophores, colorimetric methods possess the potential to quickly monitor analytes without dependence on advanced detection instruments. The colorimetric biosensors developed in previous studies are summarized in Table 3 which presents analyte-binding medium, added volume of sample, incubation time, sample matrix and LOD of respective analytical methods. Most colorimetric biosensors can obtain sensitivity values on a scale of $\mu \mathrm{g} / \mathrm{mL}$ or $\mathrm{ng} / \mathrm{mL}$ for analyzing illicit drugs. In addition, a less sample consumption is feasible with the added volume of sample in the range of $1 \mu \mathrm{L}-1.2 \mathrm{~mL}$ (mostly below $100 \mu \mathrm{L}$ ). The recognition of analyte to sensors can be also thoroughly accomplished within $30 \mathrm{~min}$. Some of methods even finished incubation of analyte less than $5 \mathrm{~min}$. For the investigation of prolonged life time of a sensor, a proper storage treatment extended the shelf-life up to 2 months without apparent signal decay [48].

\section{Nanomaterial-based fluorescent sensors}

Fluorescent detection is regarded as a more sensitive optical sensing technique than the use of a colorimetric sensing system. Conventional fluorescent organic dyes exhibit high sensitivity; however, the disadvantages of fluorescent organic dyes are their high cost and complicated synthesis procedure. In recent years, nanomaterials with fluorescent characteristics, such as NCs, QDs, CDs and UCNPs, have become new alternatives as fluorescent sensors. Several fluorescent sensing mechanisms have also been developed, including specific recognition, fluorescence resonance energy transfer (FRET) and molecular gating. The schematic diagram is shown in Fig. 2. The fluorescent sensors developed in previous studies are summarized in Table 4 which presents analyte-binding medium, added volume of sample, incubation time, sample matrix and LOD of respective analytical methods.

\subsection{Noble metal nanomaterial-based sensors}

Noble metal nanomaterials with size-dependent optical properties are an alternative to conventional fluorophores or are used as quenchers due to their high quenching ability. There were three applications of noble metal nanomaterials, including stabilizing ligand-induced fluorescent sensors, FRETbased fluorescent sensors and controlled-release fluorescent sensors.

\subsubsection{Stabilizing ligand-induced fluorescent sensors}

Metal nanoclusters (NCs) were defined as comprising several to a few hundred atoms less than approximately $1 \mathrm{~nm}$ in size. As the metal is on the same scale as the NCs, discrete energy levels can be produced. When the external energy is focused upon the NCs, fluorescence can be induced due to quantum confinement by electronic transitions between discrete energy levels. Compared to conventional organic dyes and semiconductor quantum dots, NCs possess the properties of photostability and low toxicity [16]. In addition, to stabilize the NCs that are prone to self-aggregate, several templates were used to achieve the desired outcome, including molecular ligands [57], dendrimers [58], polymers [59] and DNA [60]. Given the stability and optical properties of NCs, they are suitable for the establishment of biosensors. Furthermore, the NC technique was used to determine the presence of illegal drugs such as cocaine [61-64] and ketamine [65].

In the detection of cocaine, Zhou et al. developed two sensors based on copper nanoclusters (CuNCs) [61] and silver nanoclusters (AgNCs) [62] through the interaction between the NCs and DNA as the template. The nanocluster diameter of $\mathrm{Cu}$ can be supported only by double-strand DNA (dsDNA) with an emission wavelength of $596 \mathrm{~nm}$ and an excitation wavelength of $340 \mathrm{~nm}$. According to the specific stabilization of CuNCs by dsDNA, the aptamer can be used as a blocker against the hybridization of DNA by the addition of aptamercorresponding substances, namely, cocaine, to inhibit the formation of CuNCs. Consequently, the established aptasensor exhibited a detection limit of $30 \mathrm{ng} / \mathrm{mL}$ for cocaine. The DNA sequence with cytosine and guanine provides an ideal scaffold for the synthesis of AgNCs due to the strong affinity for silver ions. Moreover, the emitted fluorescence of AgNCs can be enhanced through close proximity to a guanine-rich DNA sequence because guanine possesses the lowest oxidation potential among nucleotides and can play the role of an electron donor to reduce the oxidized NCs to emit unoxidized NCs [66]. According to the theory of fluorescence-enhanced NCs, Zhou et al. also established an aptasensor based on AgNCs for the detection of cocaine [62]. The two oligonucleotides were designed for the synthesis of AgNCs with guaninerich sequences, and they can hybridize together to form a specific secondary structure only in the 
Table 3. Various nanomaterial-based colorimetric sensors for analysis of illicit drugs.

\begin{tabular}{|c|c|c|c|c|c|}
\hline $\begin{array}{l}\text { Nanomaterial-based colorimetric } \\
\text { sensors }\end{array}$ & Sample volume & $\begin{array}{l}\text { Incubation } \\
\text { time }^{1}\end{array}$ & Sample & Limit of detection & Ref. \\
\hline \multicolumn{6}{|c|}{ Small molecular-based AuNP sensors } \\
\hline \multirow[t]{3}{*}{ Citrate-capped AuNPs } & $1 \mathrm{~mL}$ & - & Bone & $\begin{array}{l}0.62 \mu \mathrm{g} / \mathrm{mL} \text { for } \\
\text { codeine sulfate }\end{array}$ & [34] \\
\hline & & & Bone marrow & & \\
\hline & & & Soil & & \\
\hline \multirow[t]{6}{*}{ Citrate-capped AuNPs } & $1.2 \mathrm{~mL}$ & $10 \mathrm{~min}$ & Urine & $\begin{array}{l}0.3 \mu \mathrm{g} / \mathrm{mL} \text { for } \\
\text { codeine }\end{array}$ & [35] \\
\hline & & & & $\begin{array}{l}0.3 \mu \mathrm{g} / \mathrm{mL} \text { for } \\
\text { methadone }\end{array}$ & \\
\hline & & & & $0.29 \mu \mathrm{g} / \mathrm{mL}$ for & \\
\hline & & & & $6.7 \mu \mathrm{g} / \mathrm{mL}$ for & \\
\hline & & & & noroxycodone & \\
\hline & & & & $\begin{array}{l}0.31 \mu \mathrm{g} / \mathrm{mL} \text { for } \\
\text { thebaine }\end{array}$ & \\
\hline \multirow[t]{2}{*}{ Citrate-capped AuNPs } & - & $10 \mathrm{~min}$ & Serum & $\begin{array}{l}0.15 \mu \mathrm{g} / \mathrm{mL} \text { for } \\
\text { morphine }\end{array}$ & [36] \\
\hline & & & Urine & & \\
\hline \multirow[t]{3}{*}{ Melamine-modified AuNPs } & - & $3 \mathrm{~min}$ & Blood & $\begin{array}{l}0.28 \mathrm{ng} / \mathrm{mL} \text { for } \\
\text { clonazepam }\end{array}$ & [40] \\
\hline & & & Bone & & \\
\hline & & & Bone marrow & & \\
\hline \multirow[t]{2}{*}{ Melamine-modified AuNPs } & - & $10 \mathrm{~min}$ & Serum & $\begin{array}{l}2.7 \mathrm{ng} / \mathrm{mL} \text { for } \\
\text { codeine }\end{array}$ & [41] \\
\hline & & & Urine & $\begin{array}{l}4.9 \mathrm{ng} / \mathrm{mL} \text { for } \\
\text { morphine }\end{array}$ & \\
\hline
\end{tabular}

Aptamer-based AuNP sensors

(A) Oligonucleotide-assisted aggregation

Complementary strand-

modified AuNPs and

$-\quad 10 \mathrm{~s}$

No LOD

[44]

cocaine aptamer

Aptamer sequence:

5'-ACTCATCTGTGAA

TCTCGGGAGACAAGG

ATAAATCCTTCAATGA

AGTGGGTCTCCC-3

Cocaine aptamer fragment

$10 \mu \mathrm{L}$

$30 \mathrm{~min}$

Fingerprints

$90 \mathrm{ng}$ for

1-modified AuNPs and

cocaine aptamer fragment

2-modified AuNPs

Aptamer sequence

(fragment 1): $5^{\prime}$ -

GTTCTTCAATGAAG

TGGGACGACATTT

TTTTTTT-SH-3'

Aptamer sequence

(fragment 2): 5'-

GGGAGTCAAGAAC

TTTTTTTTTT-SH-3

(B) Salt-induced self-assembly

AuNPs and cocaine aptamer $2 \mu \mathrm{L}$

2-3 $\min$

$0.6 \mu \mathrm{g} / \mathrm{mL}$

[46]

fragment $1 \& 2$

Aptamer sequence

(fragment 1): $5^{\prime}$ -

GTTCTTCAATGAAGT

GGGACGACA-3'

Aptamer sequence

(fragment 2): $5^{\prime}$ -

GGGAGTCAAGAAC-3'

AuNPs and cocaine aptamer $20 \mu \mathrm{L}$

$30 \mathrm{~min}$

Urine

$0.3 \mathrm{ng} / \mathrm{mL}$

for cocaine 
Table 3. (continued)

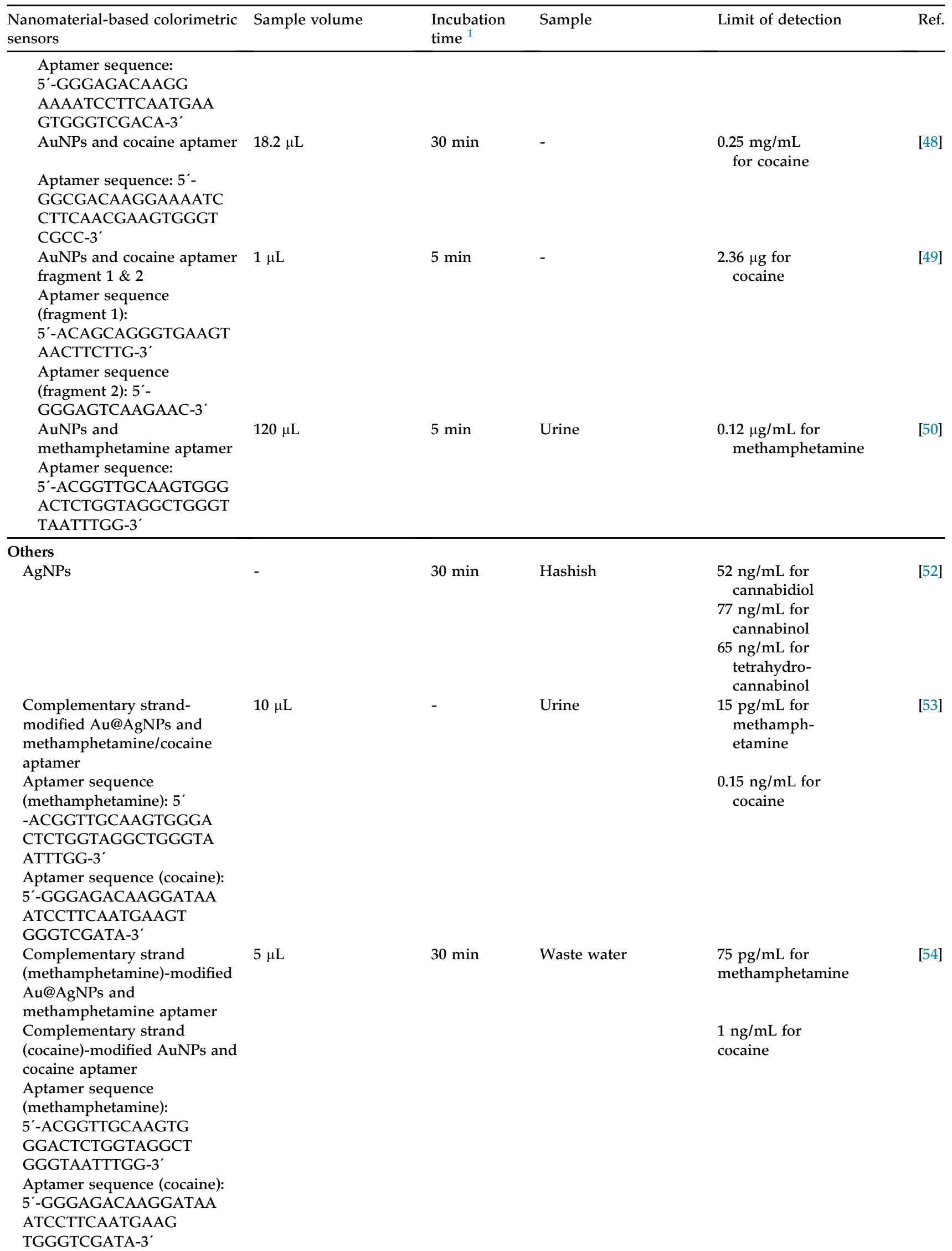


Table 3. (continued)

\begin{tabular}{|c|c|c|c|c|c|}
\hline $\begin{array}{l}\text { Nanomaterial-based colorimetric } \\
\text { sensors }\end{array}$ & Sample volume & $\begin{array}{l}\text { Incubation } \\
\text { time }{ }^{1}\end{array}$ & Sample & Limit of detection & Ref. \\
\hline $\begin{array}{l}\text { Cocaine antibody-modified } \\
\text { MNPs }\end{array}$ & $80 \mu \mathrm{L}$ & $10 \mathrm{~min}$ & Urine & $5 \mathrm{ng} / \mathrm{mL}$ for cocaine & [55] \\
\hline $\begin{array}{l}\text { Benzoylecgonine mAb } \\
\text { conjugated AuNPs }\end{array}$ & $100 \mu \mathrm{L}$ & - & Synthetic saliva & $10 \mathrm{ng} / \mathrm{mL}$ for cocaine & [56] \\
\hline
\end{tabular}

Abbreviation: AuNPs: gold nanoparticles; AgNPs: silver nanoparticles; Au@AgNPs: gold-silver core-shell nanoparticles.

${ }^{1}$ Incubation time: the time of recognition of the analyte in sensing procedure.

presence of cocaine. Finally, the LOD of cocaine was $30 \mathrm{ng} / \mathrm{mL}$.

Other aptasensors based on AgNCs were also developed. For instance, Zhang et al. established an aptasensor in combination with a nicking endonuclease-assisted signal amplification method for the detection of cocaine in serum samples with an LOD of $0.6 \mathrm{ng} / \mathrm{mL}$ [63], Sharon et al. also fabricated an aptasensor based on FRET between AgNCs and quenchers with an LOD of $91 \mathrm{ng} / \mathrm{mL}$ [64], and Ding et al. used a DNA sequence ( $\mathrm{dC12}$ ) composed of an AgNC template and ketamine-binding DNA as the scaffold for the stabilization of AgNCs. In the presence of ketamine, the DNA scaffold of the AgNCs disintegrated and further interacted with ketamine, resulting in the transformation of the DNA complex structure so that the fluorescence emitted from the AgNCs could be quenched. The LOD was $60 \mathrm{pg} / \mathrm{mL}$ [65]. A novel sensing system based on AgNCs and the technique of artificial intelligence was established for the detection of illegal drugs [67]. The sensing principle is mainly based on the change in the fluorescence of AgNCs influenced by the interaction between the analyte and AgNCs. After that, sensing statistics can be integrated by a deep learning (DL) model, which is a subfield of artificial intelligence. The DL model can be utilized to construct three-dimensional fingerprint-like spectra. The spectra are composed of recognizable peak distributions by a fluorescence excitation emission matrix while the analyte interacted with AgNCs. In this study, the spectra for illicit drugs, namely, 3,4-methylenedioxyamphetamine (MDA), MDMA, codeine, meperidine and methcathinone, were established. The novel detection technique was capable of identifying and semiquantifying these drugs down to $2 \mu \mathrm{g} / \mathrm{mL}$ and possessed the potential to rapidly identify multiple illicit drugs [67].

\subsubsection{FRET-based fluorescent sensors}

The typical principle of fluorescent sensors is mainly based on the quenching effect of the fluorophore by FRET. The excited-state energy from the

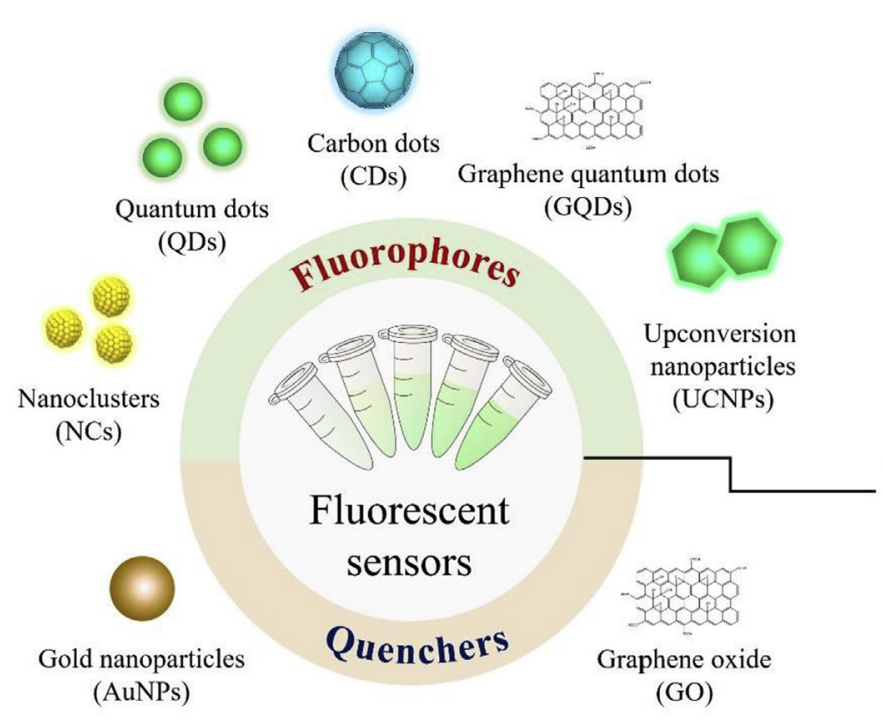

\section{Sensing mechanism}

Ligand-induction

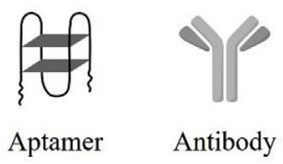

FRET

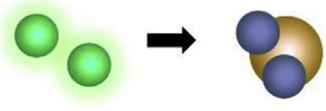

Control-release

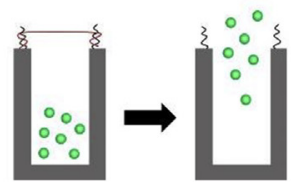

Fig. 2. Fluorometric strategies for illicit drugs based on nanomaterials which were constructed as fluorophore or quencher and utilized to establish diverse sensing mechanisms. 
Table 4. Various nanomaterial-based fluorescent sensors for analysis of illicit drugs.

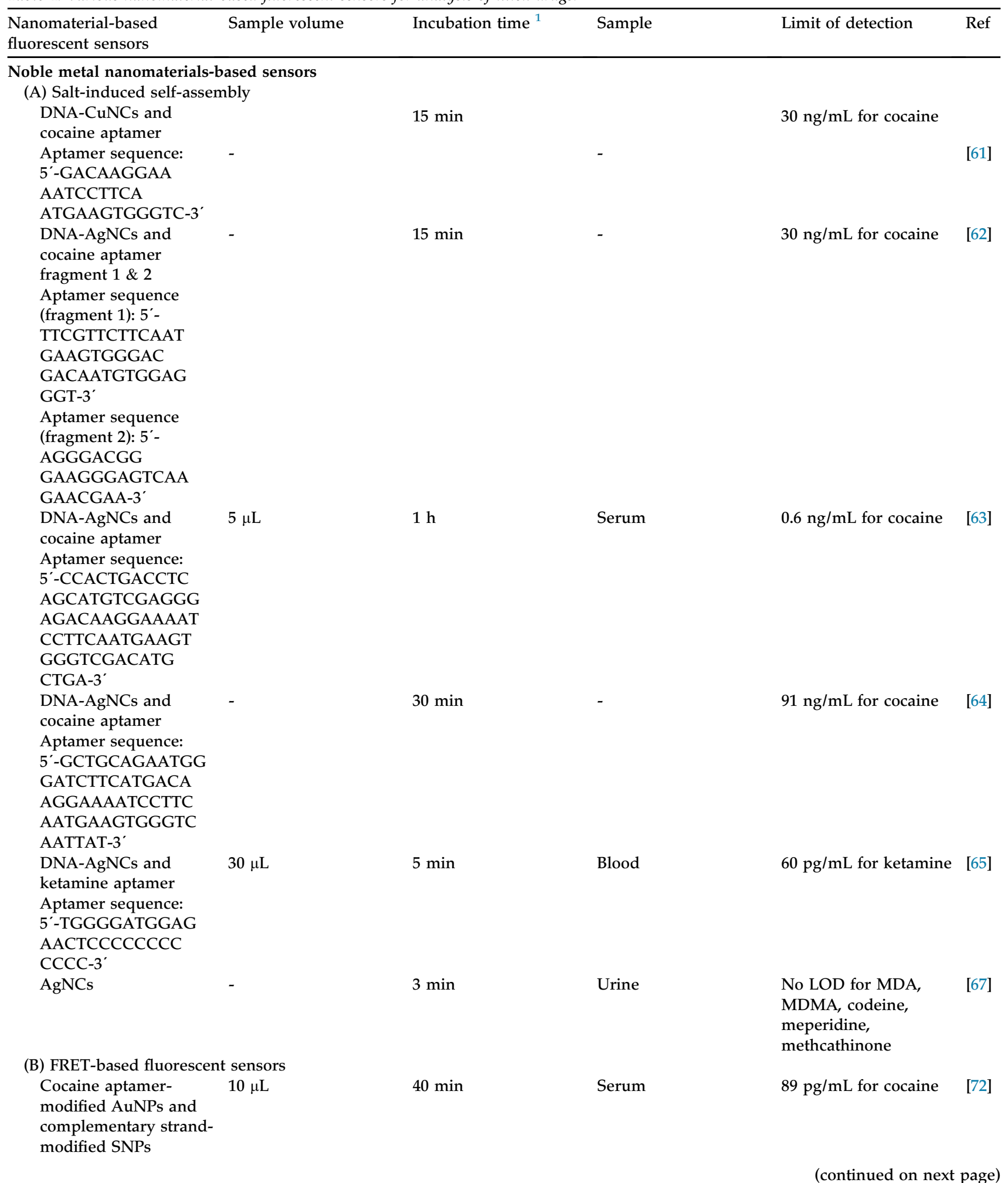


Table 4. (continued)

\begin{tabular}{|c|c|c|c|c|c|}
\hline $\begin{array}{l}\text { Nanomaterial-based } \\
\text { fluorescent sensors }\end{array}$ & Sample volume & Incubation time $^{1}$ & Sample & Limit of detection & Ref \\
\hline $\begin{array}{l}\text { Aptamer sequence: } \\
\text { 5'-CCATAGGGAGAC } \\
\text { AAGGATAAATCC } \\
\text { TTCAATGAAGTGGG } \\
\text { TCTCCC-SH-3' }\end{array}$ & & & & & \\
\hline $\begin{array}{l}\text { Complementary } \\
\text { strand-modified } \\
\text { AuNPs and cocaine } \\
\text { aptamer } \\
\text { Aptamer sequence } \\
\text { (cocaine): } \\
\text { 5'-Cy5-AAGTGGGG } \\
\text { AGACAAGGATAA } \\
\text { ATCCTTCAATGAAG } \\
\text { TGGGTCTCCC-3' }\end{array}$ & $3 \mu \mathrm{L}$ & $1 \mathrm{~h}$ & - & No LOD for cocaine & [73] \\
\hline $\begin{array}{l}\text { Cocaine aptamer and } \\
\text { AuNPs } \\
\text { Aptamer sequence } \\
\text { (cocaine aptamer } \\
\text { fragment 1): } \\
\text { 5'-AMCA-AGACAAG } \\
\text { GAAAA-3' } \\
\text { Aptamer sequence } \\
\text { (cocaine aptamer } \\
\text { fragment 2): } \\
\text { 5'-TCCTTCAATG } \\
\text { AAGTGGGTCG-3' }\end{array}$ & $5 \mu \mathrm{L}$ & $4 \mathrm{~h}$ & - & $9.1 \mathrm{ng} / \mathrm{mL}$ for cocaine & [74] \\
\hline AuNPs & - & $3 \mathrm{~min}$ & $\begin{array}{l}\text { Serum } \\
\text { Urine }\end{array}$ & $\begin{array}{l}19 \mathrm{pg} / \mathrm{mL} \text { (serum) for } \\
\text { morphine } \\
17 \mathrm{pg} / \mathrm{mL} \text { (urine) for } \\
\text { morphine }\end{array}$ & [75] \\
\hline NTS@SNPs & $29_{\text {equivalents }}$ & $5 \mathrm{~min}$ & - & $\begin{array}{l}\text { No LOD for } \\
\text { methamphetamine }\end{array}$ & [76] \\
\hline $\begin{array}{l}\text { Cocaine aptamer } \\
\text { fragment 1-modified } \\
\text { SNPs } \\
\text { and cocaine aptamer } \\
\text { fragment } 2 \\
\text { Aptamer sequence } \\
\text { (fragment 1): } 5^{\prime} \text {-biotin- } \\
\text { GGGAGTCAAGAAC- } \\
\text { BHQ-1-3' } \\
\text { Aptamer sequence } \\
\text { (fragment 2): } 5^{\prime} \text {-FAM- } \\
\text { GTTCTTCAATGAAGT } \\
\text { GTGGGACGACA- } \\
\text { TAMRA-3' }\end{array}$ & 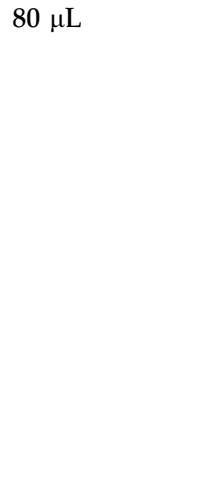 & $25 \mathrm{~min}$ & Serum & $25 \mathrm{pg} / \mathrm{mL}$ for cocaine & [77] \\
\hline (C) Control-released fluo & scent sensors & & & & \\
\hline $\begin{array}{l}\text { Pseudorotaxane } \\
\text { capped mesoporous } \\
\text { SNPs }\end{array}$ & $100 \mu \mathrm{L}$ & $2 \mathrm{~h}$ & Water & $0.94 \mu \mathrm{g} / \mathrm{mL}$ for MDMA & [79] \\
\hline $\begin{array}{l}\text { complementary } \\
\text { strand-modified NAA } \\
\text { and } \\
\text { cocaine aptamer }\end{array}$ & $100 \mu \mathrm{L}$ & $20 \mathrm{~min}$ & Saliva & $0.15 \mu \mathrm{g} / \mathrm{mL}$ for cocaine & [80] \\
\hline
\end{tabular}


Table 4. (continued)

\begin{tabular}{|c|c|c|c|c|c|}
\hline $\begin{array}{l}\text { Nanomaterial-based } \\
\text { fluorescent sensors }\end{array}$ & Sample volume & Incubation time $^{1}$ & Sample & Limit of detection & Ref \\
\hline $\begin{array}{l}\text { Aptamer sequence: } \\
\text { 5'-TTTTGGGGG } \\
\text { GGGGAGACAAG } \\
\text { GAAAATCCTTCAA } \\
\text { TGAAGTGGGT } \\
\text { CTCCAGGGGGG } \\
\text { TTTT-3' }\end{array}$ & & & & & \\
\hline \multicolumn{6}{|c|}{ Quantum dots-based fluorescent sensors } \\
\hline $\begin{array}{l}\text { morphine antibody- } \\
\text { labeled CdS@MAA-QDs }\end{array}$ & $0.2 \mu \mathrm{L}$ & - & - & No LOD for morphine & [82] \\
\hline $\begin{array}{l}\text { Morphine antibody- } \\
\text { labeled CdSe/ZnS QDs }\end{array}$ & $100 \mu \mathrm{L}$ & - & Soup & $\begin{array}{l}0.27 \mathrm{ng} / \mathrm{mL} \text { for } \\
\text { morphine }\end{array}$ & [83] \\
\hline $\begin{array}{l}\text { 7-aminoclonazepam } \\
\text { antibody-modified CdTe- } \\
\text { QDs }\end{array}$ & - & $15 \mathrm{~min}$ & Urine & $\begin{array}{l}21 \mathrm{pg} / \mathrm{mL} \text { for } 7- \\
\text { aminoclonazepam }\end{array}$ & [84] \\
\hline $\begin{array}{l}\text { Complementary strand- } \\
\text { modified QDs and } \\
\text { cocaine aptamer } \\
\text { Aptamer sequence: } \\
\text { 5'-ACTCATCTGT } \\
\text { GATATCTCGGGAGA } \\
\text { CAAGGAAAATCCTTC } \\
\text { AATGAAGTGGGT } \\
\text { CTCCC-3' }\end{array}$ & - & - & - & $0.15 \mu \mathrm{g} / \mathrm{mL}$ for cocaine & [85] \\
\hline $\begin{array}{l}\text { Complementary strand- } \\
\text { modified QDs and } \\
\text { cocaine aptamer } \\
\text { Aptamer sequence: } \\
\text { 5'-ACTCATCTGTGAAT } \\
\text { CTCGGGAGACAAG } \\
\text { GATAAATCCTTCAAT } \\
\text { GAAGTGGGTCT } \\
\text { CCC-3' }\end{array}$ & $80 \mu \mathrm{L}$ & $5 \mathrm{~min}$ & - & $36 \mu \mathrm{g} / \mathrm{mL}$ for cocaine & [86] \\
\hline $\begin{array}{l}\text { AuNPs-conjugated } \\
\text { cocaine aptamer- } \\
\text { modified QDs }\end{array}$ & $25 \mu \mathrm{L}$ & $3 \mathrm{~h}$ & Artificial urine & $40 \mathrm{pg} / \mathrm{mL}$ for cocaine & [87] \\
\hline $\begin{array}{l}\text { Aptamer sequence: } \\
5^{\prime}-\mathrm{C}_{6}-\mathrm{NH}_{2}-\mathrm{AGAC} \\
\text { AAGGAAAATCC } \\
\text { TTCAATGAAGT } \\
\text { GGGTCG-SH }{ }_{2}-\mathrm{C}_{3}-3^{\prime}\end{array}$ & & & & $\begin{array}{l}480 \mathrm{ng} / \mathrm{mL} \text { for } \\
\text { benzoylecgonine }\end{array}$ & \\
\hline $\begin{array}{l}\text { L-cysteine capped CdS } \\
\text { QDs }\end{array}$ & - & - & Urine & $\begin{array}{l}1.8 \mathrm{ng} / \mathrm{mL} \text { for } \\
\text { methamphetamine } \\
\text { (fluorescence) } \\
0.086 \mathrm{ng} / \mathrm{mL} \text { for } \\
\text { methamphetamine } \\
\text { (chemiluminescence) }\end{array}$ & 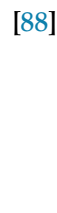 \\
\hline $\begin{array}{l}\mathrm{D} \text {-Cysteine molecules- } \\
\text { functionalized CdSe QDs }\end{array}$ & - & - & - & $\begin{array}{l}17 \mathrm{ng} / \mathrm{mL} \text { for } \mathrm{L}^{-} \\
\text {morphine }\end{array}$ & [89] \\
\hline $\begin{array}{l}\text { Streptavidin-QDs, } \\
\text { complementary strand- } \\
\text { modified AuNPs and } \\
\text { cocaine aptamer } \\
\text { Aptamer sequence: } \\
\text { 5'-ATCTCGGGAGAC } \\
\text { AAGGATAAATCC } \\
\text { TTCAATGAAGTGGG } \\
\text { TCTCCCAAAAAAAA } \\
\text { AA-Biotin-3' }\end{array}$ & $10 \mu \mathrm{L}$ & $25 \mathrm{~min}$ & - & $0.15 \mathrm{pg} / \mathrm{mL}$ for cocaine & [90] \\
\hline
\end{tabular}


Table 4. (continued)

\begin{tabular}{|c|c|c|c|c|c|}
\hline $\begin{array}{l}\text { Nanomaterial-based } \\
\text { fluorescent sensors }\end{array}$ & Sample volume & Incubation time $^{1}$ & Sample & Limit of detection & Ref \\
\hline \multicolumn{6}{|c|}{ Carbon nanomaterials-based fluorescent sensors } \\
\hline $\begin{array}{l}\text { Methamphetamine } \\
\text { aptamer-modified CDs } \\
\text { and CoOOH nanosheets } \\
\text { Aptamer sequence: } 5^{\prime}- \\
\mathrm{NH}_{2}-\left(\mathrm{CH}_{2}\right)_{6-} \\
\text { ACGGTTGCAAGT } \\
\text { GGGACTCTG GTA } \\
\text { GGCTGGGTTAAT } \\
\text { TTGG-3' }\end{array}$ & - & $20 \mathrm{~min}$ & & $\begin{array}{l}0.48 \mathrm{ng} / \mathrm{mL} \text { for } \\
\text { methamphetamine }\end{array}$ & [92] \\
\hline CDs & $1.5 \mathrm{~mL}$ & $5 \mathrm{~min}$ & Beverage & $\begin{array}{l}2.0 \mu \mathrm{g} / \mathrm{mL} \text { for } \\
\text { nitrazepam }\end{array}$ & [93] \\
\hline CDs-functionalized paper & $10 \mu \mathrm{L}$ & $10 \mathrm{~min}$ & Urine & $\begin{array}{l}1.3 \mu \mathrm{g} / \mathrm{mL} \text { for } 4- \\
\text { chloroethcathinone }\end{array}$ & [94] \\
\hline GQDs & - & $1 \mathrm{~min}$ & - & $\begin{array}{l}1.48 \mu \mathrm{g} / \mathrm{mL} \text { for } \\
\text { methamphetamine } \\
0.5 \mu \mathrm{g} / \mathrm{mL} \text { for } \\
\text { morphine }\end{array}$ & [97] \\
\hline $\begin{array}{l}\text { GQDs with antimorphine } \\
\text { (antibody) }\end{array}$ & - & - & - & $18 \mathrm{ng} / \mathrm{mL}$ for morphine & [98] \\
\hline $\begin{array}{l}\text { GO and cocaine aptamer } \\
\text { fragment } 1 \& 2 \\
\text { Aptamer sequence } \\
\text { (cocaine aptamer } \\
\text { fragment 1): } 5^{\prime}- \\
\text { GGGAGTCTCAAG } \\
\text { AAC-FAM-3' } \\
\text { Aptamer sequence } \\
\text { (cocaine aptamer } \\
\text { fragment 2): } 5^{\prime}- \\
\text { GTTCTTCAATGAAG } \\
\text { TGGGACGACTAT-3' }\end{array}$ & - & $10 \mathrm{~min}$ & Plasma & $30 \mathrm{pg} / \mathrm{mL}$ for cocaine & [101] \\
\hline $\begin{array}{l}\text { GO and cocaine aptamer } \\
\text { Aptamer sequence: } \\
\text { 5'-GGGAGACAAGGAA } \\
\text { AATCCTTCAATGAAG } \\
\text { TGGGTCTCCCTAGTT } \\
\text { TTCTAGGGAGAC-PO } 4^{-} \\
3^{\prime}\end{array}$ & $20 \mu \mathrm{L}$ & $20 \mathrm{~min}$ & Urine & $57 \mathrm{ng} / \mathrm{mL}$ for cocaine & [102] \\
\hline $\begin{array}{l}\text { Cocaine aptamer } \\
\text { fragment 1-modified } \\
\text { GQDs and cocaine } \\
\text { aptamer fragment 2- } \\
\text { modified AuNPs }\end{array}$ & $1 \mu \mathrm{L}$ & $1 \mathrm{~h}$ & Plasma & $30 \mathrm{ng} / \mathrm{mL}$ for cocaine & [103] \\
\hline $\begin{array}{l}\text { Aptamer sequence } \\
\text { (fragment 1): } \\
5^{\prime}-\mathrm{NH}_{2}-\left(\mathrm{CH}_{2}\right)_{6}{ }^{-} \\
\text {TTTTTGGGAGTCA } \\
\text { AGAACGAA-3' }\end{array}$ & & & Serum & & \\
\hline $\begin{array}{l}\text { Aptamer sequence } \\
\text { (fragment 2): } \\
5^{\prime}-\mathrm{SH}^{-}\left(\mathrm{CH}_{2}\right)_{6}^{-} \\
\text {TTCGTTCTTCAATG } \\
\text { AAGTGGGACGA } \\
\text { CA-3' }\end{array}$ & & & Saliva & & \\
\hline & & & Urine & & \\
\hline
\end{tabular}


Table 4. (continued)

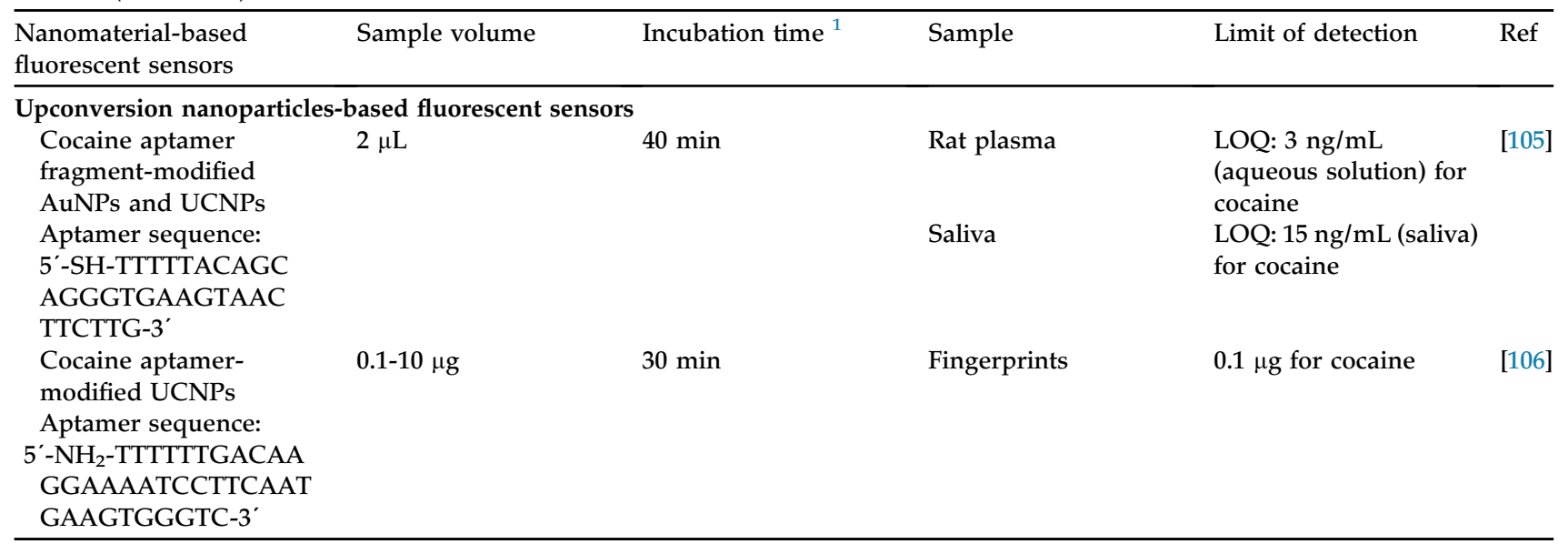

Abbreviation: CuNCs: copper nanoclusters; AgNCs: silver nanoclusters; MDA: 4,5-methylene-dioxy amphetamine; MDMA: 3,4-methylene dioxy methamphetamine; SNPs: silica nanoparticles; NTS: 4-thiophene-N-propyl(trithoxysilane)1,8-naphthalimide; NAA: nanoporous anodic alumina; MAA: mercaptoacetic acid; CDs: carbon dots; CoOOH: cobalt oxyhydroxide; GQDs: graphene quantum dots; GO: graphene oxide; UCNPs: upconversion nanoparticles.

${ }^{1}$ Incubation time: the time of recognition of the analyte in sensing procedure.

fluorophore as a donor transfers to the quencher as an acceptor-based dipole-dipole interaction in the context of the proximity between the donor and acceptor in the range from 10 to $100 \AA$ [68]. Furthermore, alternatives to quenchers, such as metal nanoparticles (AuNPs) and graphene oxide, are based on the properties of surface plasmon resonance (SPR) and heterogeneous electronic structures [69]. The heterogeneous electronic structure of graphene oxide is attributed to its composition of $\mathrm{sp}^{2}$ and $\mathrm{sp}^{3}$ binding, which provides properties of FRET and nonradiative dipole-dipole coupling $[69,70]$.

Sensors coupled with aptamers, known as aptasensors, have been developed to enhance detection selectivity. The first fluorescent aptasensor aimed at detecting cocaine was established by Stojanovic et al.[71]. The strategy of detection was based on molecular beacons that were labeled with fluorescein as the fluorophore and dabcyl as the quencher on the double end of the cocaine-specific aptamer. The aptamer can form a secondary structure after the presence of cocaine. The conformational change of the aptamer shortens the proximity between the fluorophore and the quencher, which produces fluorescent degeneration.

Gold nanoparticles (AuNPs) are ideal candidates for fluorescent quenchers with unique optical properties by surface plasmon resonance (SPR) [72-75]. The aptasensor coupled with AuNPs can be divided into unmodified and oligonucleotidemodified. For instance, Zhang et al. developed an aptasensor based on complementary aptamermodified AuNPs for the detection of cocaine [73].
The interaction between the cocaine and the fluorescent aptamer allows the aptamer to exhibit steric hindrance by forming a secondary structure with cocaine. As a result, the prehybridized fluorescent aptamer can be released, and the fluorescence can be recovered. Luo et al. developed an aptasensor based on unmodified AuNPs for the detection of cocaine [74]. The fluorescent aptamer can attach onto the surface of AuNPs with van der Waals forces, and the fluorescence will be quenched due to the close distance between the aptamer and AuNPs. In the presence of cocaine, the complex of the aptamer and cocaine becomes a secondary structure that resists the attachment to AuNPs by electrostatic repulsion [42] and allows the recovery of fluorescence. Consequently, the LOD for the detection of cocaine was $9.1 \mathrm{ng} / \mathrm{mL}$. Another fluorescent biosensor was also developed by the direct interaction between the analyte and AuNPs. Nebu et al. established a biosensor for the detection of morphine based on the competitive attachment between morphine and fluorescein onto the surface of AuNPs to influence the quenching of fluorescein by AuNPs, and this sensor had an LOD up to $17 \mathrm{pg} / \mathrm{mL}$ for urine and $19 \mathrm{pg} / \mathrm{mL}$ for serum [75].

A similar mechanism of aptasensors coupled with silica nanoparticles (SNPs) was applied for signal amplification [72,76,77]. Sarreshtehdar et al. reported an aptasensor based on AuNPs as the quencher and SNPs for the enhancement of fluorescent intensity, and the technique possessed high sensitivity, up to $89 \mathrm{pg} / \mathrm{mL}$, for the detection of cocaine in serum [72]. Rouhani reported a nanosensor based on 1,8-naphthalimide-thiophene- 
doped SNPs for the detection of methamphetamine. The interaction between 1,8-naphthalimide and methamphetamine not only triggers the exhibition of fluorescence but also enhances the sensitivity [76]; Abnous et al. also established an aptasensor based on SNPs for the detection of cocaine in serum with a limit of detection of $25 \mathrm{pg} / \mathrm{mL}$ [77].

\subsubsection{Control-released fluorescent sensors}

In addition to nanomaterials that possess optical properties to develop sensor systems, porous nanomaterials can also be utilized to construct a detection system on the basis of a molecule gate that can efficiently control the release of molecules inside the cavities of porous nanomaterials. Mesoporous silica nanoparticles (SNPs) were used to establish a sensing platform for the detection of illicit drugs. Mesoporous SNPs have many cavities on the surface, and they possess a large load capacity, biocompatibility and on-command delivery application [78]. The fundamental principle of fluorescent controlled-released SNPs is accomplished by capping the cavities by molecules and oligonucleotides to prevent the release of fluorophores in the cavities. As the analytes interact with the capping substances, the gate can be destroyed, and the fluorophores can be released. With this theory, pseudorotaxane capped mesoporous SNPs were established by Lozano-Torres et al. to detect MDMA. Detection can be accomplished depending on the competitive interaction between MDMA and pseudorotaxane, which induces the uncapping of cavities and facilitates the release of fluorescein. Consequently, an LOD of $0.94 \mu \mathrm{g} / \mathrm{mL}$ could be achieved for MDMA [79]. In addition, alumina can also be constructed as nanoporous anodic alumina (NAA), which is capable of loading small molecules. Ribes et al. fabricated an aptasensor based on NAA for cocaine that possesses cavities with an average size of $8 \mathrm{~nm}$ [80]. Likewise, the assistance of the cocaine-aptamer complex provided a molecular gate that blocked the release of fluorescent reporters, rhodamine $B$, keeping them in the cavities. In the presence of cocaine, the aptamer bound with cocaine and detached from the NAA. Subsequently, rhodamine $B$ be released from of cavities. Consequently, the quantification of cocaine can be achieved, and the LOD for cocaine was $151 \mathrm{ng} / \mathrm{mL}$ in saliva [80].

\subsection{Quantum dot-based fluorescent sensors}

Quantum dots (QDs) are nanocrystals composed of semiconducting material with a small size, mainly in the range of 2-10 $\mathrm{nm}$. The diameters of QDs are intermediate between the bulk of semiconductors and discrete molecules. Attributed to the tiny size of QDs in close proximity to the wavelength of the electron, the phenomenon of quantum confinement effects is due to the energy gap between the valence band and the conducting band. The size-dependent band gap provides the optical and electronic properties of QDs, such as excitation and electron-hole interactions, which lead to photoluminescence $[17,81]^{-}$With the property of fluorescent exhibition, QDs have been used in the development of many sensors for the detection of various substances in a wide variety of industries, such as the environment, biology, and medicine. Moreover, QD techniques in combination with other techniques, such as immunoassays [82-84] and aptamers [85-87], have also been used to detect illegal drugs in recent research, and these techniques are considered reliable and useful tools for the establishment of trace analytical methods.

In the development of sensors simply based on the modification of QDs, Hassanzadeh et al. developed a sensor based on ${ }_{L}$-cysteine capped CdS QDs for the detection of methamphetamine. The interaction of methamphetamine to the surface of the QDs, which can affect the efficiency of fluorescent emission and an LOD of $1.8 \mathrm{ng} / \mathrm{mL}$, can be obtained in a urine sample [88]. Similarly, the sensor based

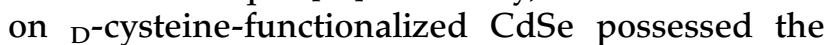
selectivity of chiral analyte on the detection of $\mathrm{L}^{-}$ morphine with the LOD at $17 \mathrm{ng} / \mathrm{mL}$ [89]. Furthermore, the surfaces of QDs modified with an antimorphine antibody and denatured bovine serum albumin were also established as immunosensors for the detection of morphine [82,83] and 7-aminoclonazepam [84].

Aptasensors coupled with QDs were also utilized to detect cocaine. Two aptasensors, one based on QDs and Cy5 and the other based on QDs, Cy5 and Iowa Black $R Q$, were established through the mechanism of FRET for the detection of cocaine [85]. In the aptasensor based on QDs and Cy5, the QD surface was modified with a short sequence of oligonucleotides that can hybridize with the cocaine aptamer, and Cy5 was modified on another partly complementary sequence of the cocaine aptamer. The Cy5-modified complementary sequence of cocaine aptamer can hybridize with the cocaine aptamer, and the mechanism of FRET was further instigated by the energy transfer from the QDs to Cy5 with an excitation wavelength at $488 \mathrm{~nm}$ in the absence of cocaine. After the addition of cocaine, the aptamer can form a specific secondary structure that resists hybridization between the cocaine aptamer and the Cy5-modified complementary aptamer. 
Therefore, FRET cannot be induced, and the emission signal of QDs at $605 \mathrm{~nm}$ can be observed. Finally, the aptasensor had a detection limit of $0.15 \mu \mathrm{g} / \mathrm{mL}$. The CdSe/ZnS core-shell QDs were used as the fluorophore and AuNPs were used as the quencher for the detection of cocaine and benzoylecgonine. The analytical method successfully quantified the analytes with an LOD of $41 \mathrm{pg} / \mathrm{mL}$ for cocaine and $0.48 \mu \mathrm{g} / \mathrm{mL}$ for benzoylecgonine in artificial urine [87]. In addition, the technique in combination with QDs, aptamers and AuNPs was also developed by Zhang et al. The aptamer-modified microfluidic beads served as the main body of the sensing platform [90]. Complementary-aptamer DNA-AuNPs (cDNA-AuNPs) loaded with horseradish peroxidase (HRP) were used as the medium to trigger the interaction between tyramine-biotin and streptavidin-QDs. The linkage of biotin-streptavidin provided strong fluorescence to microbeads due to the numerous QDs bound to them. However, the interaction failed to function properly in the presence of cocaine because cocaine can occupy the hybridized sites of the cDNA-AuNPs to microbeads so that further reaction will be interrupted. Finally, an LOD of $0.15 \mathrm{pg} / \mathrm{mL}$ could be achieved for cocaine through this method [90].

\subsection{Carbon nanomaterial-based fluorescent sensors}

The development of carbon nanomaterials has drawn great attention to the application of sensing systems as they have less toxicity and environmental hazards than QDs. Carbon nanomaterials that are widely used in the establishment of biosensors can be divided into three parts: carbon dots (CDs), graphene quantum dots (GQDs) and graphene oxide (GO).

Quantum-sized carbon nanoparticles, known as CDs, possess the stable property of photoluminescence. The principle of photoluminescence from CDs may be caused by the presence of surface energy traps that become emissive upon stabilization because of surface passivation $[18,91]$. Saberi et al. developed an aptasensor using CDs as the fluorophore and cobalt oxyhydroxide nanosheets $(\mathrm{CoOOH})$ as the quencher for the detection of methamphetamine and a schematic illustration of the aptasensor [92]. The CDs were synthesized from the grape leaves by hydrothermal treatment and were further immobilized onto the aptamer of methamphetamine. The CD-modified aptamer can attach onto the surface of the $\mathrm{CoOOH}$ nanosheet by van der Waals forces in the absence of methamphetamine, and the fluorescence emitted from the $\mathrm{CDs}$ was quenched by $\mathrm{CoOOH}$ through FRET. In contrast, the aptamer can conjugate with methamphetamine, and the complex can resist the interaction between the aptamer and the $\mathrm{CoOOH}$ nanosheet. Consequently, fluorescence can be observed, and the limit of detection of methamphetamine was measured to be $0.48 \mathrm{ng} / \mathrm{mL}$ in human plasma. Furthermore, the fluorescence emitted from CDs can also be quenched according to the absorption of the target onto the surface of CDs. The attachment of the target to CDs triggers electron transfer, which depends on the functional groups of the analyte, and further FRET occurs. Yen et al. developed a biosensor based on CDs for the detection of nitro-containing benzodiazepines, namely, nimetazepam, which is regarded as a type of date rape drug. This method provides an LOD for nimetazepam at $2.13 \mu \mathrm{g} / \mathrm{mL}$ in beverages such as beer, juice, wine and whiskey [93]. Likewise, CDs were also modified onto paper for the detection of 4chloroethcathinone and a LOD can be obtained to be $1.3 \mu \mathrm{g} / \mathrm{mL}$ in urine sample [94].

Similar to the CDs, GQDs also possess the optical property of photoluminescence with significant quantum confinement and edge effects as the size of GQDs is below $100 \mathrm{~nm}[95,96]$. Different from the spherical nanoparticles of CDs composed of $\mathrm{sp}^{3}$ hybridized carbon, the GQDs are composed of $\mathrm{sp}^{2}$ hybridized carbon, which represents a layer of crystalline structure. A sensor based on GQDs was designed for the detection of $\mathrm{D}^{- \text {-methamphetamine }}$ and $\mathrm{L}$-morphine through their interaction with GQDs. The quenching effect was observed by the addition of methamphetamine. Meanwhile, the fluorescence enhancement effect was found by the addition of morphine. The limits of detection for $\mathrm{D}^{-}$ methamphetamine and $\mathrm{L}_{\mathrm{L}}$-morphine were $1.48 \mu \mathrm{g} /$ $\mathrm{mL}$ and $0.5 \mu \mathrm{g} / \mathrm{mL}$, respectively [97]. Furthermore, the LOD of morphine was improved to $18 \mathrm{ng} / \mathrm{mL}$ by using GQDs modified with antimorphine [98].

Apart from quantum dot-characterized carbon materials, another widely applied technique is graphene oxide (GO), which is a thin sheet of graphite fabricated by "top-down [99]" or "bottom-up [100]" methods. GO possesses the property of quenching the fluorescent species by FRET or nonradiative dipole-dipole coupling as the distance between the GO and fluorophore is less than approximately $20 \mathrm{~nm}$. Moreover, the ionic groups and aromatic groups of GO allow charged species such as proteins and DNA to attach onto the GO surface by electrostatic interactions and $\pi-\pi$ stacking, respectively [69]. Consequently, GO can easily capture fluorescent substances to produce quenching effects. GO was used in the development of a biosensor for the detection of cocaine in body fluids, 
namely, urine, plasma, serum and saliva [101-103]. Zhang et al. established an aptasensor based on GO as the quencher and exonuclease III (Exo III) for signal amplification [101]. Exo III was a crucial factor in the feasibility of the aptasensor, which possessed the property of cleaving the 3-hydroxyl termini of mononucleotides from double-stranded DNA and acted from the $3^{\prime}$ to $5^{\prime}$ direction [104]. In the presence of cocaine, the aptamer can bind with the cocaine and form a specific secondary structure. Subsequently, the partly complementary DNA sequence corresponding to the aptamer can be further hybridized with the folding structure to form double-stranded DNA. The addition of Exo III can cleave the complementary DNA modified with FAM into mononucleotides. Therefore, FAM failed to attach to the surface of GO, and fluorescence was observed. On the other hand, the complementary DNA can attach onto the surface of GO in the absence of cocaine, and the quenching of fluorescence was achieved. The biosensor was established with an LOD of $30 \mathrm{pg} / \mathrm{mL}$ in the plasma sample.

\subsection{Upconversion nanoparticle-based fluorescent sensors}

In recent years, nanomaterials constructed by rare earth elements such as yttrium $(\mathrm{Y})$, ytterbium $(\mathrm{Yb})$ and erbium (Er), namely, upconversion nanoparticles (UCNPs), have been utilized as biosensors. Attributed to the composition of rare earth elements, UCNPs possess the unique trait of emitting ultraviolet/visible (UV/Vis) light under nearinfrared excitation, which efficiently circumvents interference. This property is achieved through intraconfigurational transitions by rare earth elements with abundant energy levels that allow continuous energy transition from low level excitation to high level emission [19]. In addition, the surface of UCNPs is compatible with modifying substances such as oligonucleotides and polymers. He et al. constructed a portable UCNP-based paper device coupled with aptamer-modified AuNPs for the prompt detection of cocaine free from the laboratory. The cellulose filter paper device was immobilized with PEI-UCNPs and $\mathrm{NH}_{2}$-anticocaine aptamer fragments. Another fragment of anti-cocaine aptamers was modified onto AuNPs, which acted as a quencher to diminish the luminescence of UCNPs. In the presence of cocaine, two aptamer fragments can link together and shorten the distance between AuNPs and UCNPs. As a result, the luminescence can be quenched, and cocaine quantification can be accomplished with LOQs of $3 \mathrm{ng} / \mathrm{mL}$ and $15 \mathrm{ng} / \mathrm{mL}$ in aqueous solution and saliva, respectively [105]. In addition, UCNPs were also used for LFP detection. Wang et al. developed an aptasensor based on aptamermodeled UCNPs as signal reporters of LFP for the detection of cocaine, and the method was able to be used to monitor the content of cocaine down to $0.1 \mu \mathrm{g}$ [106].

In summary of nanomaterial-based fluorescent sensors, the utilization of nanomaterials in an analytical method provides superior detection efficiency for monitoring illicit drugs. LODs of analytes can be measured down to the range of $\mathrm{pg} / \mathrm{mL}$ and $\mathrm{ng} / \mathrm{mL}$. Furthermore, less sample consumption of approximately $100 \mu \mathrm{L}$ can be also obtained in most established methods. For incubation time of analyte to sensor, some methods can accomplish the reaction within $10 \mathrm{~min}$ which achieve the strategy of rapid detection.

\section{Conclusion}

Attributed to the development of analytical strategies coupled with nanomaterials, features of prompt monitoring, high sensitivity, economical equipment and simple manipulation can be acquired. These advantages provide efficient detection techniques for illicit drugs in bodily fluids and the environment. This review summarizes the application of nanomaterials with respect to the establishment of analytical methods divided into sample pretreatment, colorimetric and fluorescent sensors. Sample pretreatment methods using metal magnetic nanoparticles offer high extraction efficiency with short-term consumption and target specificity, which is more straightforward than traditional sample preparation methods. Colorimetric methods were mainly based on the unique optical properties of AuNPs and AgNPs with representative extinction wavelengths that can change following their aggregation. Fluorescent sensors were also successfully developed by the assistance of fluorophores, namely, NCs, QDs, CDs, UCNPs and quenchers such as AuNPs, CNTs and GO. In addition to these detection strategies, nanomaterials can also be utilized to analytical methods based on surface enhanced raman scattering (SERS) for illicit drugs which were investigated in other literature $[107,108]$. With the application of nanomaterials for illicit drugs, numerous innovative methods can be constructed in combination with other techniques, such as antibodies, aptamers, MIPs, chip (paper) devices and artificial intelligence. Some of these methods even provide high sensitivity up to $\mathrm{pg} / \mathrm{mL}$, similar to the performance of conventional sophisticated instruments. Among these detection methods for 
illicit drugs, many of them were combined with aptamers, which possess high compatibility with nanomaterials and can be utilized to improve specificity. However, aptamers for illicit drugs have not been sufficiently established because the majority of analytical methods with the assistance of aptamers were developed for cocaine and methamphetamine, while a minority were developed for codeine and ketamine. Aptamers corresponding to other illegal drugs remain incompletely developed, especially for those that have been prevalent in recent years, such as cannabis and morphine. The establishment of analytical methods coupled with aptamers is still considered a potential approach to facilitate the monitoring of a wide variety of forensic drugs. Although the clinical detection of forensic drugs currently relies on immunoassays and sophisticated instruments such as HPLC-MS and GCMS, novel biosensors in combination with nanotechnology are expected to realistically monitor forensic drugs in the future.

\section{Conflict of interest}

The authors have declared no conflict of interest.

\section{Acknowledgements}

We gratefully acknowledge the support of the Ministry of Science and Technology of Taiwan (MOST 109-2113-M-194 -011) for funding this work.

\section{References}

[1] Houck MM, Siegel JA. Illicit Drugs Fundam Forensic Sci. Elsevier; 2015. p. 315-52.

[2] United Nations Office on Drugs and Crime. World Drug Report 2019. United Nations publication; 2019. Sales No. E.19.XI.8.

[3] Lee SF, Hsu J, Tsay WI. The trend of drug abuse in Taiwan during the years 1999 to 2011. J Food Drug Anal 2013;21: 390-6.

[4] Taiwan Food and Drug Administration. National health interview and drug abuse survey. Taiwan. 2018.

[5] Standard inspection procedure for benzodiazepines (6830SIP-DP-BEU). Taiwan. 2019.

[6] Executive Yuan Department of Health. Enforcement regulations for urine test of abused drugs. Taiwan. 2014.

[7] Schulze H, Schumacher $M$, Urmeew R, Alvarez J, Bernhoft IM, deGier HG, et al. Driving Under the Influence of Drugs, Alcohol and Medicines in Europe-findings from the DRUID project. 2012. p. 1-58.

[8] US Department of Health and Human Services et al.. Mandatory guidelines for federal workplace drug testing programs. Fed Regist 2017;82:7920-70.

[9] US Department of Health and Human Services et al.. Mandatory guidelines for federal workplace drug testing programs-oral/fluid. Fed Regist 2019;84:57554-600.

[10] Peters FT. Recent advances of liquid chromatography(tandem) mass spectrometry in clinical and forensic toxicology. Clin Biochem 2011;44:54-65.
[11] Hernández F, Ibáñez M, Bade R, Bijlsma L, Sancho JV. Investigation of pharmaceuticals and illicit drugs in waters by liquid chromatography-high-resolution mass spectrometry. TrAC - Trends Anal Chem 2014;63:140-57.

[12] Molnár B, Molnár-Perl I. The role of alkylsilyl derivatization techniques in the analysis of illicit drugs by gas chromatography. Microchem J 2015;118:101-9.

[13] Moore KA, Werner C, Zannelli RM, Levine B, Smith ML. Screening postmortem blood and tissues for nine cases of drugs of abuse using automated microplate immunoassay. Forensic Sci Int 1999;106:93-102.

[14] Liz-Marzán LM. Tailoring surface plasmons through the morphology and assembly of metal nanoparticles. Langmuir 2006;22:32-41.

[15] Zhang Z, Wang H, Chen Z, Wang X, Choo J, Chen L. Plasmonic colorimetric sensors based on etching and growth of noble metal nanoparticles: Strategies and applications. Biosens Bioelectron 2018;114:52-65.

[16] Díez I, Ras RHA. Few-Atom Silver Clusters as Fluorescent Reporters. Berlin, Heidelberg: Springer; 2010. p. 307-32.

[17] Yoffe AD. Semiconductor quantum dots and related systems: Electronic, optical, luminescence and related properties of low dimensional systems. Adv Phys 2001;50:1-208.

[18] Sun YP, Zhou B, Lin Y, Wang W, Fernando KAS, Pathak P, et al. Quantum-sized carbon dots for bright and colorful photoluminescence. J Am Chem Soc 2006;128:7756-7.

[19] Sun L-D, Dong H, Zhang P-Z, Yan C-H. Upconversion of Rare Earth Nanomaterials. Annu Rev Phys Chem 2015;66: 619-42.

[20] Safarikova M, Safarik I. Magnetic solid-phase extraction. J Magn Magn Mater 1999;194:108-12.

[21] Giakisikli G, Anthemidis AN. Magnetic materials as sorbents for metal/metalloid preconcentration and/or separation. A review. Anal Chim Acta 2013;789:1-16.

[22] Taghvimi A, Hamishehkar H. Carbon coated magnetic nanoparticles as a novel magnetic solid phase extraction adsorbent for simultaneous extraction of methamphetamine and ephedrine from urine samples. J Chromatogr B Anal Technol Biomed Life Sci 2017;1041-1042:113-9.

[23] Taghvimi A, Dastmalchi S, Javadzadeh Y. Novel Ceramic Carbon-Coated Magnetic Nanoparticles as Stir Bar Sorptive Extraction Coating for Simultaneous Extraction of Amphetamines from Urine Samples. Arab J Sci Eng 2019;44: 6373-80.

[24] Yang F, Zou Y, Ni C, Wang R, Wu M, Liang C, et al. Magnetic dispersive solid-phase extraction based on modified magnetic nanoparticles for the detection of cocaine and cocaine metabolites in human urine by HPLCMS. J Sep Sci 2017;40:4234-45.

[25] Boojaria A, Masrournia M, Ghorbani H, Ebrahimitalab A, Miandarhoie M. Silane modified magnetic nanoparticles as a novel adsorbent for determination of morphine at trace levels in human hair samples by high-performance liquid chromatography with diode array detection. Forensic Sci Med Pathol 2015;11:497-503.

[26] Haeri SA, Abbasi S, Sajjadifar S. Bio-dispersive liquid liquid microextraction based on nano rhaminolipid aggregates combined with magnetic solid phase extraction using Fe3O4@PPy magnetic nanoparticles for the determination of methamphetamine in human urine. J Chromatogr B Anal Technol Biomed Life Sci 2017;1063:101-6.

[27] Zhang S, Cui Y, Sun J, Xi Y, Zhang C, Tang J. Sensitive magnetic solid-phase microextraction based on oxide multiwalled carbon-nanotubes for the determination of methylamphetamine and ketamine in human urine and blood. Anal Methods 2015;7:4209-15.

[28] DosSantos RR, Nunes Paiva MJ, Veloso JC, Serp P, Lourdes Cardeal ZDe, Menezes HC. Efficient extraction method using magnetic carbon nanotubes to analyze cocaine and benzoylecgonine in breast milk by GC/MS. Bioanalysis 2017;9:1655-66.

[29] Abdolmohammad-Zadeh H, Zamani A, Shamsi Z. Preconcentration of morphine and codeine using a magnetite/ 
reduced graphene oxide/silver nano-composite and their determination by high-performance liquid chromatography. J Chromatogr A 2019;1590:2-9.

[30] Taghvimi A, Hamishehkar H, Ebrahimi M. The application of magnetic nano graphene oxide in determination of methamphetamine by high performance liquid chromatography of urine samples. J Iran Chem Soc 2016;13: 1471-80.

[31] Du Y, Li B, Guo S, Zhou Z, Zhou M, Wang E, et al. GQuadruplex-based DNAzyme for colorimetric detection of cocaine: Using magnetic nanoparticles as the separation and amplification element. Analyst 2011;136:493-7.

[32] $\mathrm{Wu} \mathrm{KR}$, Hsiao HH. Rapid and accurate quantification of amphetamine and methamphetamine in human urine by antibody decorated magnetite nanoparticles coupled with matrix-assisted laser desorption ionization time-of-flight mass spectrometer analysis. Anal Chim Acta 2018;1025: 134-40.

[33] Kelly KL, Coronado E, Zhao LL, Schatz GC. The optical properties of metal nanoparticles: The influence of size, shape, and dielectric environment. J Phys Chem B 2003;107: 668-77.

[34] Lodha A, Pandya A, Sutariya PG, Menon SK. A smart and rapid colorimetric method for the detection of codeine sulphate, using unmodified gold nanoprobe. RSC Adv 2014; 4:50443-8.

[35] Mohseni N, Bahram M, Baheri T. Chemical nose for discrimination of opioids based on unmodified gold nanoparticles. Sensors Actuators, B Chem 2017;250:509-17.

[36] Bahram M, Madrakian T, Alizadeh S. Simultaneous colorimetric determination of morphine and ibuprofen based on the aggregation of gold nanoparticles using partial least square. J Pharm Anal 2017;7:411-6.

[37] Thanh NTK, Green LAW. Functionalisation of nanoparticles for biomedical applications. Nano Today 2010;5: 213-30.

[38] Gittins DI, Caruso F. Spontaneous Phase Transfer of Nanoparticulate Metals from Organic to Aqueous Media. Angew Chemie Int Ed 2001;40:3001-4.

[39] Chi H, Liu B, Guan G, Zhang Z, Han MY. A simple, reliable and sensitive colorimetric visualization of melamine in milk by unmodified gold nanoparticles. Analyst 2010;135:1070-5.

[40] Lodha A, Pandya A, Sutariya PG, Menon SK. Melamine modified gold nanoprobe for on-spot colorimetric recognition of clonazepam from biological specimens. Analyst 2013;138:5411-6.

[41] Mohseni N, Bahram M. Mean centering of ratio spectra for colorimetric determination of morphine and codeine in pharmaceuticals and biological samples using melamine modified gold nanoparticles. Anal Methods 2016;8:6739-47.

[42] $\mathrm{Li} \mathrm{H}$, Rothberg L. Colorimetric detection of DNA sequences based on electrostatic interactions with unmodified gold nanoparticles. Proc Natl Acad Sci U S A 2004;101:14036-9.

[43] Elghanian R, Storhoff JJ, Mucic RC, Letsinger RL, Mirkin CA. Selective colorimetric detection of polynucleotides based on the distance-dependent optical properties of gold nanoparticles. Science 1997;277:1078-81.

[44] Liu J, Lu Y. Fast colorimetric sensing of adenosine and cocaine based on a general sensor design involving aptamers and nanoparticles. Angew Chemie - Int Ed 2005; 45:90-4.

[45] Li K, Qin W, Li F, Zhao X, Jiang B, Wang K, et al. Nanoplasmonic imaging of latent fingerprints and identification of cocaine. Angew Chemie - Int Ed 2013;52:11542-5.

[46] Zhang J, Wang L, Pan D, Song S, Boey FYC, Zhang H, et al. Visual cocaine detection with gold nanoparticles and rationally engineered aptamer structures. Small 2008;4: 1196-200.

[47] Soh JH, Lin Y, Rana S, Ying JY, Stevens MM. Colorimetric Detection of Small Molecules in Complex Matrixes via Target-Mediated Growth of Aptamer-Functionalized Gold Nanoparticles. Anal Chem 2015;87:7644-52.
[48] Smith JE, Leny JK, Hagen JA, Chávez JL, KelleyLoughnane N, Griffin DK. Colorimetric detection with aptamer-gold nanoparticle conjugates coupled to an android-based color analysis application for use in the field. Talanta 2014;121:247-55.

[49] Wang L, Musile G, McCord BR. An aptamer-based paper microfluidic device for the colorimetric determination of cocaine. Electrophoresis 2018;39:470-5.

[50] Shi Q, Shi Y, Pan Y, Yue Z, Zhang H, Yi C. Colorimetric and bare eye determination of urinary methylamphetamine based on the use of aptamers and the salt-induced aggregation of unmodified gold nanoparticles. Microchim Acta 2014;182:505-11.

[51] Stojanovic MN, DePrada P, Landry DW. Fluorescent sensors based on aptamer self-assembly. J Am Chem Soc 2000; 122:11547-8.

[52] Amjadi M, Sodouri T. A Surface Plasmon Resonance-Based Method for Detection and Determination of Cannabinoids Using Silver Nanoparticles. J Appl Spectrosc 2014;81:232-7.

[53] Mao K, Yang Z, Li J, Zhou X, Li X, Hu J. A novel colorimetric biosensor based on non-aggregated Au@Ag core-shell nanoparticles for methamphetamine and cocaine detection. Talanta 2017;175:338-46.

[54] Mao K, Ma J, Li X, Yang Z. Rapid duplexed detection of illicit drugs in wastewater using gold nanoparticle conjugated aptamer sensors. Sci Total Environ 2019;688:771-9.

[55] Wu J, Dong M, Zhang C, Wang Y, Xie M, Chen Y, et al. Magnetic Lateral Flow Strip for the Detection of Cocaine in Urine by Naked Eyes and Smart Phone Camera. Sensors 2017;17:1286.

[56] Guler E, Yilmaz Sengel T, Gumus ZP, Arslan M, Coskunol H, Timur S, et al. Mobile Phone Sensing of Cocaine in a Lateral Flow Assay Combined with a Biomimetic Material. Anal Chem 2017;89:9629-32.

[57] Bao Y, Yeh HC, Zhong C, Ivanov SA, Sharma JK, Neidig ML, et al. Formation and stabilization of fluorescent gold nanoclusters using small molecules. J Phys Chem C 2010;114:15879-82.

[58] Zheng J, Petty JT, Dickson RM. High quantum yield blue emission from water-soluble Au8 nanodots. J Am Chem Soc 2003;125:7780-1.

[59] Shang L, Dong S. Facile preparation of water-soluble fluorescent silver nanoclusters using a polyelectrolyte template. Chem Commun 2008:1088.

[60] Guo W, Yuan J, Dong Q, Wang E. Highly sequencedependent formation of fluorescent silver nanoclusters in hybridized DNA duplexes for single nucleotide mutation identification. J Am Chem Soc 2010;132:932-4.

[61] Zhou Z, Du Y, Dong S. Double-strand DNA-templated formation of copper nanoparticles as fluorescent probe for label-free aptamer sensor. Anal Chem 2011;83:5122-7.

[62] Zhou Z, Du Y, Dong S. DNA-Ag nanoclusters as fluorescence probe for turn-on aptamer sensor of small molecules. Biosens Bioelectron 2011;28:33-7.

[63] Zhang K, Wang K, Zhu X, Zhang J, Xu L, Huang B, et al. Label-free and ultrasensitive fluorescence detection of cocaine based on a strategy that utilizes DNA-templated silver nanoclusters and the nicking endonuclease-assisted signal amplification method. Chem Commun 2014;50: 180-2.

[64] Sharon E, Enkin N, Albada HB, Willner I. Aptasensors based on supramolecular structures of nucleic acid-stabilized Ag nanoclusters. Chem Commun 2015;51:1100-3.

[65] Ding Y, Li X, Guo Y, Yan J, Ling J, Li W, et al. Rapid and sensitive detection of ketamine in blood using novel fluorescence genosensor. Anal Bioanal Chem 2017;409: 7027-34.

[66] Yeh H-C, Sharma J, Han JJ, Martinez JS, Werner JH. A DNA-Silver Nanocluster Probe That Fluoresces upon Hybridization. Nano Lett 2010;10:3106-10.

[67] Ju L, Lyu A, Hao H, Shen W, Cui H. Deep learning-assisted three-dimensional fluorescence difference spectroscopy for 
identification and semiquantification of illicit drugs in biofluids. Anal Chem 2019;91:9343-7.

[68] Yuan P, Walt DR. Calculation for Fluorescence Modulation by Absorbing Species and Its Application to Measurements Using Optical Fibers. Anal Chem 1987;59:2391-4.

[69] Loh KP, Bao Q, Eda G, Chhowalla M. Graphene oxide as a chemically tunable platform for optical applications. Nat Chem 2010;2:1015-24.

[70] Mkhoyan KA, Contryman AW, Silcox J, Stewart DA, Eda G, Mattevi $\mathrm{C}$, et al. Atomic and electronic structure of graphene-oxide. Nano Lett 2009;9:1058-63.

[71] Stojanovic MN, dePrada P, Landry DW. Aptamer-based folding fluorescent sensor for cocaine. J Am Chem Soc 2001; 123:4928-31.

[72] Sarreshtehdar A, Mohammad N, Ramezani M, Mohammad S, Abnous K. A novel fluorescent aptasensor based on hairpin structure of complementary strand of aptamer and nanoparticles as a signal amplification approach for ultrasensitive detection of cocaine. Biosens Bioelectron 2016;79:288-93.

[73] Zhang J, Wang L, Zhang H, Boey F, Song S, Fan C. Aptamer-based multicolor fluorescent gold nanoprobes for multiplex detection in homogeneous solution. Small 2010;6: 201-4.

[74] Luo F, Zheng L, Chen S, Cai Q, Lin Z, Qiu B, et al. An aptamer-based fluorescence biosensor for multiplex detection using unmodified gold nanoparticles. Chem Commun 2012;48:6387-9.

[75] Nebu J, Anjali Devi JS, Aparna RS, Aswathy B, Aswathy AO, Sony G. Fluorometric determination of morphine via its effect on the quenching of fluorescein by gold nanoparticles through a surface energy transfer process. Microchim Acta 2018:185.

[76] Rouhani S, Haghgoo S. A novel fluorescence nanosensor based on 1,8-naphthalimide-thiophene doped silica nanoparticles, and its application to the determination of methamphetamine. Sensors Actuators, B Chem 2015;209: 957-65.

[77] Abnous K, Danesh NM, Ramezani M, Taghdisi SM, Emrani AS. A novel amplified double-quenching aptasensor for cocaine detection based on split aptamer and silica nanoparticles. Anal Methods 2018;10:3232-6.

[78] Climent E, Martínez-Máñez R, Sancenón F, Marcos MD, Soto J, Maquieira A, et al. Controlled delivery using oligonucleotide-capped mesoporous silica nanoparticles. Angew Chemie - Int Ed 2010;49:7281-3.

[79] Lozano-Torres B, Pascual L, Bernardos A, Marcos MD, Jeppesen JO, Salinas Y, et al. Pseudorotaxane capped mesoporous silica nanoparticles for 3,4-methylenedioxymethamphetamine (MDMA) detection in water. Chem Commun 2017;53:3559-62.

[80] À Ribes, Xifré-Pérez E, Aznar E, Sancenón F, Pardo T, Marsal LF, et al. Molecular gated nanoporous anodic alumina for the detection of cocaine. Sci Rep 2016;6:1-9.

[81] Neikov OD, Yefimov NA. Nanopowders. 2nd ed. Elsevier Ltd.; 2019.

[82] Masteri-Farahani M, Khademabbasi K, Mollatayefeh N. A selective morphine nanosensor derived from functionalized CdS quantum dots. Mater Lett 2018;228:68-71.

[83] Zhang C, Han Y, Lin L, Deng N, Chen B, Liu Y. Development of Quantum Dots-Labeled Antibody Fluorescence Immunoassays for the Detection of Morphine. J Agric Food Chem 2017;65:1290-5.

[84] Chen W, Peng C, Jin Z, Qiao R, Wang W, Zhu S, et al. Ultrasensitive immunoassay of 7-aminoclonazepam in human urine based on CdTe nanoparticle bioconjugations by fabricated microfluidic chip. Biosens Bioelectron 2009;24: 2051-6.

[85] Zhang CY, Johnson LW. Single quantum-dot-based aptameric nanosensor for cocaine. Anal Chem 2009;81:3051-5.

[86] Liu J, Jung HL, Lu Y. Quantum dot encoding of aptamerlinked nanostructures for one-pot simultaneous detection of multiple analytes. Anal Chem 2007;79:4120-5.
[87] Guler E, Bozokalfa G, Demir B, Gumus ZP, Guler B, Aldemir E, et al. An aptamer folding-based sensory platform decorated with nanoparticles for simple cocaine testing. Drug Test Anal 2017;9:578-87.

[88] Hassanzadeh J, Khataee A, Lotfi R. Sensitive fluorescence and chemiluminescence procedures for methamphetamine detection based on CdS quantum dots. Microchem J 2017; 132:371-7.

[89] Masteri-Farahani M, Mollatayefeh N. Chiral colloidal CdSe quantum dots functionalized with cysteine molecules: New optical nanosensor for selective detection and measurement of morphine. Colloids Surfaces A Physicochem Eng Asp 2019;569:78-84.

[90] Zhang H, Hu X, Fu X. Aptamer-based microfluidic beads array sensor for simultaneous detection of multiple analytes employing multienzyme-linked nanoparticle amplification and quantum dots labels. Biosens Bioelectron 2014;57:22-9.

[91] Zhu S, Meng Q, Wang L, Zhang J, Song Y, Jin H, et al. Highly photoluminescent carbon dots for multicolor patterning, sensors, and bioimaging. Angew Chemie - Int Ed 2013;52:3953-7.

[92] Saberi Z, Rezaei B, Faroukhpour H, Ensafi AA A fluorometric aptasensor for methamphetamine based on fluorescence resonance energy transfer using cobalt oxyhydroxide nanosheets and carbon dots. Microchim Acta 2018:185.

[93] Yen YTe, Lin YS, Chen TH, Chyueh SC, Chang HT. A Carbon-Dot Sensing Probe for Screening of Date Rape Drugs: Nitro-containing Benzodiazepines. Sensors Actuators, B Chem 2020:305.

[94] Yen YTe, Lin YS, Chen TY, Chyueh SC, Chang HT. Carbon dots functionalized papers for high-throughput sensing of 4-chloroethcathinone and its analogues in crime sites. R Soc Open Sci 2019;6.

[95] Ponomarenko LA, Schedin F, Katsnelson MI, Yang R, Hill EW, Novoselov KS, et al. Chaotic Dirac billiard in graphene quantum dots. Science 2008;320:356-8.

[96] Pan D, Zhang J, Li Z, Wu M. Hydrothermal route for cutting graphene sheets into blue-luminescent graphene quantum dots. Adv Mater 2010;22:734-8.

[97] Masteri-Farahani M, Askari F. Design and photophysical insights on graphene quantum dots for use as nanosensor in differentiating methamphetamine and morphine in solution. Spectrochim Acta - Part A Mol Biomol Spectrosc 2019;206:448-53.

[98] Masteri-Farahani M, Mosleh N. Functionalization of graphene quantum dots with antimorphine: Design of selective nanosensor for detection of morphine. Mater Lett 2019;241: 206-9.

[99] Hummers WS, Offeman RE. Preparation of Graphitic Oxide. J Am Chem Soc 1958;80:1339.

[100] Tang L, Li X, Ji R, Teng KS, Tai G, Ye J, et al. Bottom-up synthesis of large-scale graphene oxide nanosheets. J Mater Chem 2012;22:5676-83.

[101] Zhang Y, Sun Z, Tang L, Zhang H, Zhang GJ. Aptamer based fluorescent cocaine assay based on the use of graphene oxide and exonuclease III-assisted signal amplification. Microchim Acta 2016;183:2791-7.

[102] Qiu L, Zhou H, Zhu W, Qiu L, Jiang J, Shen G, et al. A novel label-free fluorescence aptamer-based sensor method for cocaine detection based on isothermal circular stranddisplacement amplification and graphene oxide absorption. New J Chem 2013;37:3998-4003.

[103] Shi Y, Dai H, Sun Y, Hu J, Ni P, Li Z. Fluorescent sensing of cocaine based on a structure switching aptamer, gold nanoparticles and graphene oxide. Analyst 2013;138:7152-6.

[104] Mol CD, Kuo CF, Thayer MM, Cunningham RP, Tainer JA Structure and function of the multifunctional DNA-repair enzyme exonuclease III. Nature 1995;374:381-6.

[105] He M, Li Z, Ge Y, Liu Z. Portable Upconversion Nanoparticles-Based Paper Device for Field Testing of Drug Abuse. Anal Chem 2016;88:1530-4. 
[106] Wang J, Wei T, Li X, Zhang B, Wang J, Huang C, et al. Nearinfrared-light-mediated imaging of latent fingerprints based on molecular recognition. Angew Chemie - Int Ed 2014;53:1616-20.

[107] Li YS, Church JS. Raman spectroscopy in the analysis of food and pharmaceutical nanomaterials. J Food Drug Anal 2014;22:29-48.
[108] Lad AN, Pandya A, Agrawal YK. Overview of nano-enabled screening of drug-facilitated crime: A promising tool in forensic investigation. TrAC - Trends Anal Chem 2016;80: $458-70$. 